Article

\title{
Coordinated Dispatch of Integrated Energy Systems Considering the Differences of Multiple Functional Areas
}

\author{
Liusong $\mathrm{Li}^{1}{ }^{1}$, Weichao Jin ${ }^{1}$, Meiyan Shen ${ }^{1}$, Li Yang ${ }^{1, *}$, Fei Chen ${ }^{2}$, Lei Wang ${ }^{2}$, Chao Zhu ${ }^{2}$, \\ Haiwei Xie ${ }^{1}$, Yating $\mathrm{Li}^{1}$ and Tianhan Zhang ${ }^{1}$ \\ 1 School of Electrical Engineering, Zhejiang University, Hangzhou 310027, China; lls9399@163.com (L.L.); \\ weichaojin@aliyun.com (W.J.); meiyanshen@aliyun.com (M.S.); haiweixie@aliyun.com (H.X.); \\ yatingli@aliyun.com (Y.L.); zhangtianhan@aliyun.com (T.Z.) \\ 2 State Grid Zhejiang Economic Research Institute, Hangzhou 310027, China; chen_fei@sohu.com (F.C.); \\ wang_lei1@zj.sgcc.com.cn (L.W.); 13735257360@139.com (C.Z.) \\ * Correspondence: eeyangli@zju.edu.cn; Tel.: +86-571-8795-1542
}

Received: 11 April 2019; Accepted: 18 May 2019; Published: 22 May 2019

\begin{abstract}
A large amount of wind turbine power and photovoltaic power is abandoned in many areas with abundant renewable energy due to thermal-electric coupling, inadequate local consumption capacity, and limited capacity of transmission lines, etc. To solve the above problems, a coordinated dispatching method for integrated energy systems is proposed in this paper. Firstly, the spatiotemporal characteristics of diversified loads in multiple functional areas are introduced, including the inertia and elasticity of heating/cooling loads, the spatiotemporal distribution of electric vehicles, and the optimum transmission distance of diversified loads, etc. Secondly, a coordinated dispatching model of integrated energy systems is proposed, which considers the differences of multiple functional areas and various forms of energy systems. Finally, an actual distribution system in Jianshan District, Haining, Zhejiang Province of China is investigated for demonstrating the effectiveness of the proposed model. The results illustrate that the proposed model could effectively improve the consumption rate of renewable energy and reduce the volatility of renewable energy by considering the coordination of electric vehicles, tie lines, and heating/cooling systems in multiple functional areas.
\end{abstract}

Keywords: integrated energy system; distribution system; multiple functional areas; coordinated dispatch; heating system; cooling system; electric vehicle; renewable energy

\section{Introduction}

With the increasing proportion of renewable energy in the whole energy supply, its consumption has increasingly become one of key problems to be solved, and the abandonment of wind turbine (WT) power and photovoltaic (PV) power has not been solved [1]. According to the statistics of the National Energy Administration of China, the annual abandonment of WT power in China reached 41.9 billion $\mathrm{kWh}$ in 2017 [2]. The abandonment rate of WT power in some areas of China has exceeded $40 \%$. The western region is an important area for the development of PV power in China and its installed PV capacity is still growing rapidly, but the average abandonment rate of PV power in China has reached $20 \%$.

The reasons for the abandonment of WT and PV powers are different from place to place, mainly due to the factors such as thermal-electric coupling, inadequate local consumption capacity, and limitation of transmission line capacity [3,4]. Taking Jianshan District, Haining, Zhejiang Province of China as an example, in 2018, the total installed capacity of WT and PV power in this region was $230 \mathrm{MW}$, and its load level was only around $150 \mathrm{MW}$, which is a typical area with abundant renewable 
energy. Under normal circumstances, the area basically achieves self-balancing of electric power. But under special circumstances, the loads of the industrial area during the holidays, for example, are drastically reduced, and it is impossible to achieve self-balancing of electric power. The excess energy could only be transferred back to the $220 \mathrm{kV}$ Anjiang Substation through the $110 \mathrm{kV}$ Jianshan Substation, or even be transferred to the transmission system through the $220 \mathrm{kV}$ Anjiang Substation. However, due to the capacity limitation of the main transformer in the Jianshan Substation, the Jianshan distribution systems cannot fully meet the needs of the delivery of the excess renewable energy. The limited capacity of WT and PV has reached $97 \mathrm{MW}$, and the limited proportion has reached $42.17 \%$.

The integrated energy system (IES) coordinates the various forms of energy systems such as the distribution systems, the renewable energy systems, and the traffic systems considering electric vehicles (EVs) and the combined cooling, heating, and power (CCHP) systems, which could realize the optimal utilization of various types of energy and effectively solve the consumption problem of renewable energy [5]. In [6], the optimization of the IES including district heating, cooling, and various forms of energy storage in Singapore was performed, and the results show that the cost of energy through methane storage or heat storage is much less than that of using electricity storage or hydrogen storage when the space constraints of photovoltaic installations are taken into consideration. In $[7,8]$, the consumption rate of WT in the CCHP systems is improved through energy storage, the output of the CCHP units is reduced when the WT surges, and the energy storage device is utilized to meet the user's cooling and heating demand for reducing the abandoned power of WT.

Generally, the installation costs of energy storage devices are relatively high and energy storage devices cannot consume renewable energy very well when their installed capacity is small. However, the cooling loads and the heating loads have natural energy storage characteristics as flexible resources, and there is no costly problem, which could replace part of energy storage devices. However, most of the existing research considers a given heating/cooling load curve, and the energy storage characteristics of the heating/cooling systems are not fully considered. In [9], the heat storage characteristics of the heating pipeline are coordinated with the operation of the power systems, and the thermal-electric decoupling is performed to realize flexible heating for improving the consumption rate of WT. In [10], a coordinated dispatch strategy of the combined heat and power (CHP) unit, electric heating device, and electric energy storage device is presented, and the simulation results show that the thermal systems with large inertia time constant could effectively suppress the volatility of renewable energy and reduce its impacts on the power system. In [11], a calculation method for the energy storage capacity of the heating network is proposed, and the thermal inertia of the heating network is utilized to replace the energy storage for saving financial costs and coping with the uncertainty of renewable energy.

Furthermore, the energy storage characteristics of EVs could be utilized to improve the consumption rate of renewable energy. In [12], an integrated utilization mode of EVs and PV is proposed to improve the self-distribution rate of PV generation in a small microgrid. In [13], the integration utilization of EVs, $\mathrm{PV}$, and energy storage is analyzed economically. However, the impacts of the spatiotemporal distribution characteristics of EVs on the consumption of renewable energy have not been paid much attention.

The above research works have made some progress in the economic dispatching of IES and the consumption of renewable energy, but they all focused on a single area, while the characteristics of various loads are greatly different in multiple functional areas. If the complementary characteristics of different functional areas are neglected, it is inevitable that the consumption of renewable energy is limited and the economic efficiency cannot approach to an optimal one. In [14], the IESs of multiple areas are connected through the distribution network and the heating network to form an integrated energy microgrid. In [15], the interaction of heating networks between areas with different load characteristics is analyzed, and the connection through the heating network is established to maintain the balance between the supply and demand through multiple regional IESs. In [16], for the peak-to-valley staggering phenomenon of cooling, heating, and electric loads in each subarea, the optimal energy dispatching strategy is proposed by coordinating the heating/cooling output of the CCHP systems in subareas to match the heating/cooling demands of the area. However, when the relative distance 
of each functional area is large, it is not suitable to utilize the heating/cooling networks to realize the connections between the functional areas due to the economic transmission distance problem of the heating/cooling loads.

Few studies have considered multiarea IES dispatching and there is little consideration of the different load characteristics of different areas. Considering the different characteristics of multiple functional areas and different energy systems, a coordinated dispatching model of IESs is proposed in this paper. Through the complementarity of various energy systems and different loads in multiple functional areas, the absorption rate of renewable energy can be effectively improved.

The remainder of this paper is organized as follows. In Section 2, the spatiotemporal characteristics of diversified loads in multiple functional areas are introduced, including the inertia and elasticity of heating/cooling loads, the spatiotemporal distribution of electric vehicles, and the optimum transmission distance of diversified loads, etc. In Section 3, a coordinated dispatching model of IESs is proposed, which considers the differences of multiple functional areas and various forms of energy systems. In Section 4 , the numerical results are described and discussed. In Section 5, the conclusions are presented.

\section{Spatiotemporal Characteristics of Diversified Loads in Multiple Functional Areas}

The same types of economic and social activities are highly concentrated in an urban space, forming different functional areas. Every functional area is the carrier for realizing various functions of a city. The functional areas are divided into four categories in this paper as in [17]: residential, office, commercial, and industrial areas.

The social functions, architectural features, land use types, and geographical distribution of different functional areas are different. The main characteristics of various functional areas are as follows:

The function of residential area is mainly for people to live, so its buildings are mainly ordinary residential buildings, with some green land and small shopping areas. The proportion of residential land in residential areas should be more than $50 \%$. Residential areas are usually located in the city center and suburbs.

The main functions of the office area are for administrative office, conference reception, and financial services. Therefore, its buildings are mainly office buildings and financial buildings. The office space in the office area generally exceeds $60 \%$. The office area is usually in the center of the city.

The main functions of the business district are for shopping, catering, leisure, and entertainment, so its buildings mainly consist of shopping malls. The proportion of commercial land in commercial areas should be more than $60 \%$. Business districts are usually located in the city center.

The function of industrial zones is mainly for industrial production, so it mainly consists of factory buildings. The proportion of industrial land in industrial zones should be more than $40 \%$. Industrial zones are generally located in remote suburbs.

\subsection{Characteristics of the Loads Suitable for Internal Transmission in Functional Areas}

\subsubsection{Characteristics of the Heating Loads}

Since the propagation medium of the heating systems is generally hot water or steam with low speed, there is a large time inertia constant in the heating systems, meaning the transmission of the heating loads are delayed, and a heating system composed of heating source, heating network, and heating building has a large heating inertia, which means a heating system has a certain 'storage' capability for heating energy, and its 'energy storage' effect depends on its heating inertia. This heating inertia could be utilized to coordinate with the operation of the power system. A heating network could store heating power, so the heat supply could be controlled on the time scale and then thermal-electric decoupling could be realized and the consumption rate of renewable energy could be improved. The human body's perception of temperature has ambiguity. When the temperature rises or drops in a certain range, heating users are difficult to detect, which could improve the flexible adjustability of the heating loads.

The temperature of a heat transfer medium gradually decreases with the increase of the distance during a transmission process, so the transmission distance of heating loads is limited, and it is generally 
considered that high efficiency of central heating is attained within 5-8 km [18]. Since each functional area is relatively large, it is not appropriate to establish a heating network between functional areas, but a heating network could be built inside each functional area to achieve the balance of heating loads. The characteristics of heating loads vary in different functional areas. For example, the heating loads of the residential area, the office area, and the commercial area are mostly ordinary heating loads, while the heating loads of the industrial area are mostly productive heating loads.

The elasticity of ordinary heating loads can be judged by the predicted mean vote (PMV), which represents the average value of the thermal sensation of most people in the same environment. The PMV index [19] is divided into seven levels corresponding to the seven thermal sensations of the human body, as shown in Table 1:

Table 1. Seven levels of the predicted mean vote (PMV) index corresponding to the seven thermal sensations.

\begin{tabular}{cccccccc}
\hline Thermal Sensation & Cold & Cool & Slightly Cool & Comfortable & Slightly Warm & Warm & Hot \\
\hline The PMV Index & -3 & -2 & -1 & 0 & +1 & +2 & +3 \\
\hline
\end{tabular}

The mathematical equation for the PMV index [20] is represented as

$$
\begin{aligned}
\lambda_{\mathrm{PMV}} & =\left(0.303 \mathrm{e}^{-0.036 M}+0.028\right)\left\{M-W-3.05 \times 10^{-3} \times\left[5733-6.99(M-W)-P_{\mathrm{a}}\right]-0.42[(M-W)-58.15]\right. \\
& \left.-1.7 \times 10^{-5} M\left(5867-P_{\mathrm{a}}\right)-0.0014 M\left(34-t_{\mathrm{a}}\right)-3.96 \times 10^{-8} f_{\mathrm{cl}}\left[\left(t_{\mathrm{cl}}+273\right)^{4}-\left(t_{\mathrm{b}}+273\right)^{4}\right]-f_{\mathrm{cl}} h_{\mathrm{c}}\left(t_{\mathrm{cl}}-t_{\mathrm{a}}\right)\right\}
\end{aligned}
$$

The heating supply is focused in this paper, and temperature is the most intuitive experience of the human body for indoor thermal comfort. Therefore, except for the air temperature around the human body, the other parameters are given.

When the PMV index is 0 , it corresponds to the optimal thermal comfort state of the indoor thermal environment. The PMV index should be between -1 and +1 [21], which means that it is allowed to be slightly cool and slightly warm, so the heating demand and the heating supply do not have to be strictly balanced in real-time, and it could be satisfied within a certain range.

The thermal inertia [22] could be described by the autoregressive and moving average (ARMA) model as

$$
\begin{gathered}
T_{\mathrm{h}, t}=\sum_{j=1}^{J} \alpha_{j} T_{\mathrm{n}, t-j}+\sum_{j=0}^{J} \beta_{j} T_{\mathrm{g}, t-j}+\sum_{j=0}^{J} \gamma_{j} T_{\mathrm{w}, t-j} \\
T_{\mathrm{n}, t}=\theta_{1} T_{\mathrm{n}, t-1}+\phi_{1} T_{\mathrm{g}, t-1}+\omega_{1} T_{\mathrm{w}, t-1}
\end{gathered}
$$

It shows that the indoor temperature of a heating building in a certain period of time is the result of the combined action of heat supply of the heating network in the past several periods.

The PMV index is not applicable to evaluate the elasticity of productive heating loads, so the constraints of heating loads in the industrial area are different from other functional areas.

It is assumed that the flexibility of the heating loads in the industrial area satisfies: the heat provided by the heating systems $\left(H_{\mathrm{G}, t}\right)$ at time $t$ can fluctuate within a certain range of the heating loads $\left(H_{\mathrm{L}, t}\right)$; during the time period $T^{\prime}$, the heat supplied by the heating systems is the same as the heating loads. Then, the constraints of heating loads in the industrial area can be represented as

$$
\begin{gathered}
\mu_{1} H_{\mathrm{L}, t} \leq H_{\mathrm{G}, t} \leq \mu_{2} H_{\mathrm{L}, t} \\
\sum_{t=n}^{n+T^{\prime}} H_{\mathrm{G}, t}=\sum_{t=n}^{n+T^{\prime}} H_{\mathrm{L}, t}
\end{gathered}
$$

$T^{\prime}=1$ means that the heat is supplied strictly according to the user's optimal demand, and the larger the $T^{\prime}$, the larger the time scale the heating supply and demand can be adjusted on. In this paper, it is assumed that $T^{\prime}=3$. 


\subsubsection{Characteristics of the Cooling Loads}

The temporal characteristic of the cooling systems is similar to that of the heating systems. There is large time inertia constant and a certain 'energy storage' capacity in the cooling systems. Its 'energy storage' capacity is affected by the inertia of the cooling systems. The indoor temperature of the current period is affected by the indoor temperature, the outdoor temperature, and the cooling power of the previous several periods. The cooling systems can change the cooling loads from a curve to an interval on the time scale by utilizing the inertia of the cooling systems.

Unlike centralized heating, centralized cooling has low efficiency, and it just can be efficiently transmitted within $1 \mathrm{~km}$ [23]. Considering that the relative distance between the inner parts of each functional area has exceeded the distance suitable for centralized cooling, the cooling loads are usually supplied by distributed cooling systems and balanced within each functional area. There are two main kinds of refrigerators which are common cooling loads: electric refrigerators and lithium bromide absorption refrigerators. Lithium bromide absorption refrigerators can directly utilize excess heat or waste heat to refrigerate. However, when the waste heat energy of heating network is less and does not necessarily cover the demand area of cooling loads, and renewable energy is dispersed and has surplus output, an electric chiller is suitable to realize distributed cooling. The cooling loads of different functional areas also have different characteristics. In this paper, the cooling loads of winter are mainly considered; therefore, cold storages and warehouses in the commercial area and the industrial area are the main cooling loads. A cooling load also has a certain elastic range for its environmental temperature requirements, and the requirements of different functional areas are different. For example, the temperature of commercial cold storage of meat and aquatic products should be $-10^{\circ} \mathrm{C} \sim-18^{\circ} \mathrm{C}$, and that of industrial warehouse of goods should be $-15^{\circ} \mathrm{C} \sim-20^{\circ} \mathrm{C}$.

The dynamic temperature characteristics of cooling systems [24] can be described by the Equivalent Thermal Parameters (ETP) model as

$$
\widetilde{T}_{\mathrm{n}, t}=\widetilde{T}_{\mathrm{w}, t}-Q_{\mathrm{L}, t} D-\left[\widetilde{T}_{\mathrm{w}, t}-Q_{\mathrm{L}, t} D-\widetilde{T}_{\mathrm{n}, t-1}\right] \cdot \mathrm{e}^{-\frac{\Delta t}{D C}}
$$

It shows that the indoor temperature of a cooling building in a certain period of time is the result of the combined action of cold supply of the cooling system in the past several periods.

\subsection{Characteristics of the Loads Suitable for Transmission accross Functional Areas}

\subsubsection{Characteristics of the Electric Loads}

Unlike heating/cooling loads, which have natural energy storage characteristics, the electric loads have low elasticity and have no inertia. Generally, the flexibility of power supply systems can only be increased through demand response such as interruptible loads.

For the different functional areas, the electric loads also show great differences, and there is a clear phenomenon of peak-valley staggering. Because the electric loads have the advantages of fast transmission and low losses in long-distance transmission, it is possible to establish tie lines between functional areas and realize the complementary balance of electric loads in the whole area, which can utilize the different characteristics of the electric loads in each functional area to improve the consumption of renewable energy.

\subsubsection{Characteristics of the Charging Loads of EVs}

The energy storage capacity of EV batteries allows their charging demand to be met within a certain period of time, which means that the charging loads of EVs could be shifted on the time scale. The owners of EVs have certain flexibility in the choice of charging time, and the charging loads have certain controllability.

At the same time, as a means of transportation, the spatial distribution of EVs in each functional area is closely related to its travel law. The transferability of EVs in different places could be utilized to 
establish links between functional areas. Similar to a virtual power network, the charging demand of EVs could be adjusted according to the different functional areas and time periods. The orderly charging of EVs through reasonable dispatching could effectively improve the consumption rate of renewable energy and suppress the volatility of renewable energy.

According to the results of a parking demand survey in Zhejiang Province of China [25], daily dispatching is divided into three time periods in this paper, which are represented by $k=1,2,3$, respectively. It is assumed that EVs are located in all functional areas of a region during the dispatching period. The distribution probability of EVs in each time period for different functional areas is shown in Table 2.

Table 2. Distribution probability of electric vehicles (EVs) in each time period for different functional areas.

\begin{tabular}{ccccc}
\hline Time Period & Residential Area & Office Area & Commercial Area & Industrial Area \\
\hline 8 a.m.-5 p.m. & 0.1 & 0.4 & 0.1 & 0.4 \\
6 p.m.-9 p.m. & 0.4 & 0.2 & 0.3 & 0.1 \\
10 p.m.-7 a.m. & 0.7 & 0.1 & 0.1 & 0.1 \\
\hline
\end{tabular}

The charging loads of $R$ functional areas and $T$ dispatching periods can be regarded as virtual energy storage. The relationship between the charging power and charging capacity of EVs can be described as

$$
\begin{gathered}
E_{r, t+1}=E_{r, t}+\eta_{\mathrm{ch}} P_{\mathrm{ch}, r, t} \Delta t \\
\alpha_{r, k}^{\min } E_{r, k}^{a v} \leq \sum_{t \in k} E_{r, t} \leq \alpha_{r, k}^{\max } E_{r, k}^{a v} \\
P_{\mathrm{ch}, r, t}^{\min } \leq P_{\mathrm{ch}, r, t} \leq P_{\mathrm{ch}, r, t}^{\max } \\
(1-\lambda) \sum_{r=1}^{R} \sum_{t=1}^{T} \eta_{\mathrm{ch}} P_{\mathrm{ch}, r, t}^{0} \Delta t \leq \sum_{r=1}^{R} \sum_{t=1}^{T} \eta_{\mathrm{ch}} P_{\mathrm{ch}, r, t} \Delta t \leq(1+\lambda) \sum_{r=1}^{R} \sum_{t=1}^{T} \eta_{\mathrm{ch}} P_{\mathrm{ch}, r, t}^{0} \Delta t
\end{gathered}
$$

The constraint of continuous change of charging capacity is described in (7). The constraint of the upper and lower limits of charging capacity of EVs in the same time period of area $r$ is described in (8). The constraint of the upper and lower limits of charging power of EVs can be expressed as (9). It is ensured that the total charge loads after optimal dispatching of EVs in the whole areas meet the forecasted charging loads within a certain range in (10).

\subsection{Comparisons of Spatiotemporal Characteristics of Diversified Loads in Multiple Functional Areas}

\subsubsection{Heating Loads}

The typical heating load rate curves of multiple functional areas are shown in Figure 1. The $x$-axis represents $24 \mathrm{~h}$ of the day. 


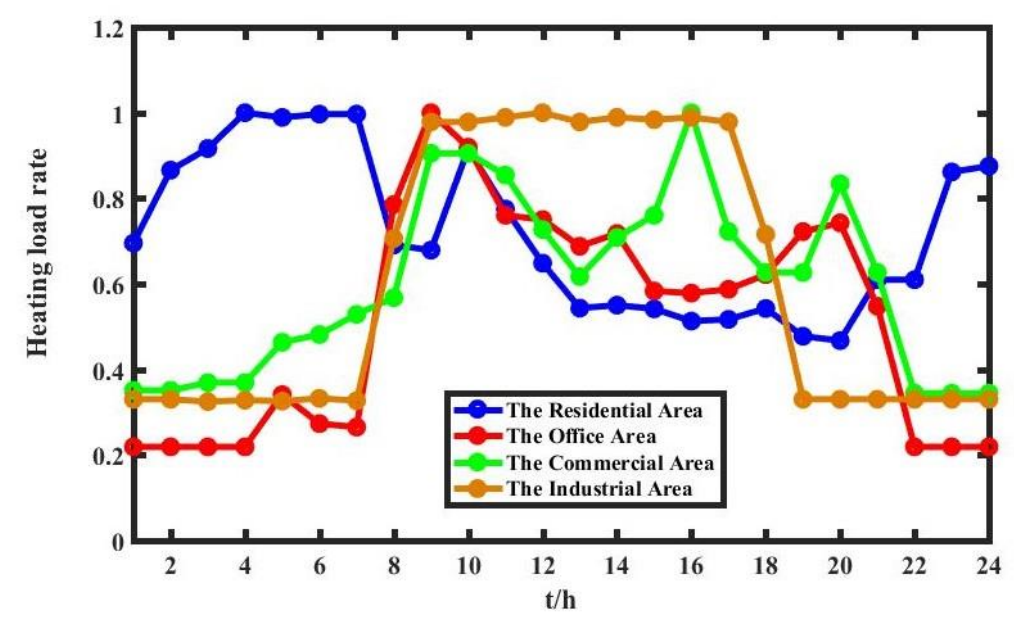

Figure 1. Typical heating load rate curves of multiple functional areas.

It can be seen from Figure 1 that the peak period of heating loads in the residential area occurs at night, while in the daytime it is lower, which is in line with the living habits of residents going out in the morning and going back home in the evening. In the office area, the heating loads are higher in working hours from 8 a.m. to 5 p.m., and in overtime from 6 p.m. to 9 p.m. In the commercial area, the heating loads are higher during the business period and lower during the nonbusiness period. The heating loads in the industrial area are mostly productive heating loads. The heating load rate is very high from 8 a.m. to 5 p.m. during the operation period of the factories, and relatively low at night due to the shutdown of some factories.

\subsubsection{Cooling Loads}

The typical cooling load rate curves of multiple functional areas are shown in Figure 2. The $x$-axis represents $24 \mathrm{~h}$ of the day.

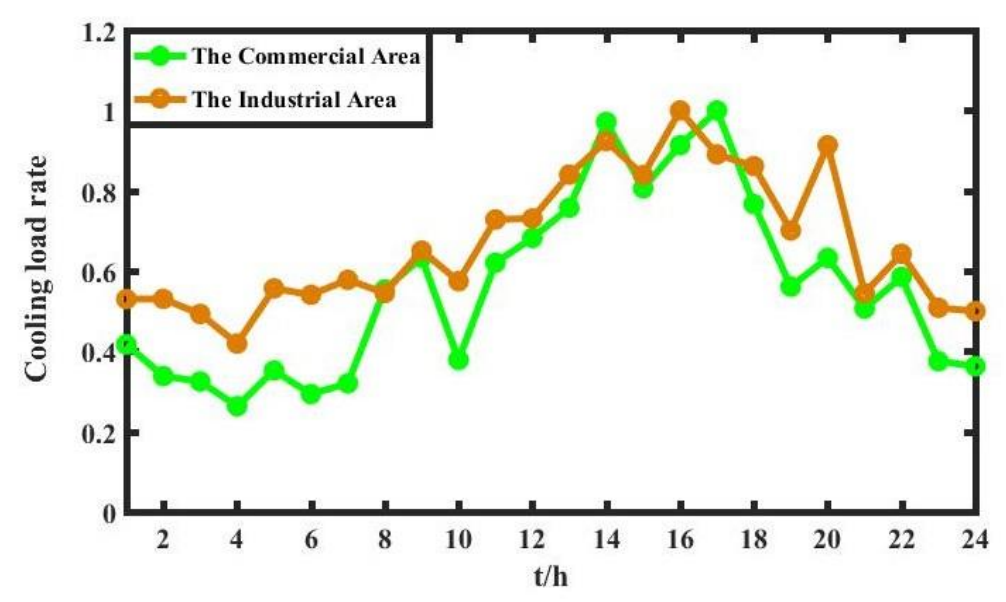

Figure 2. Typical cooling load rate curves of multiple functional areas.

It can be seen from Figure 2 that the cooling loads only exist in the commercial area and the industrial area, and the variation characteristics of cooling loads in these two functional areas are relatively similar. Due to the higher outdoor temperature, the cooling load rate is higher in the daytime and lower at night. The cooling load rate reaches the full day peak around 2 p.m. -4 p.m. The temperature requirement of storage cooling loads is much stricter in the industrial area than in the commercial area, which is the reason why the storage cooling load curve seems smoother in the former area. 


\subsubsection{Electric Loads}

Referring to the analysis method of daily loads curves in [26], typical electrical load rate curves of the four functional areas are shown in Figure 3. The $x$-axis represents $24 \mathrm{~h}$ of the day.

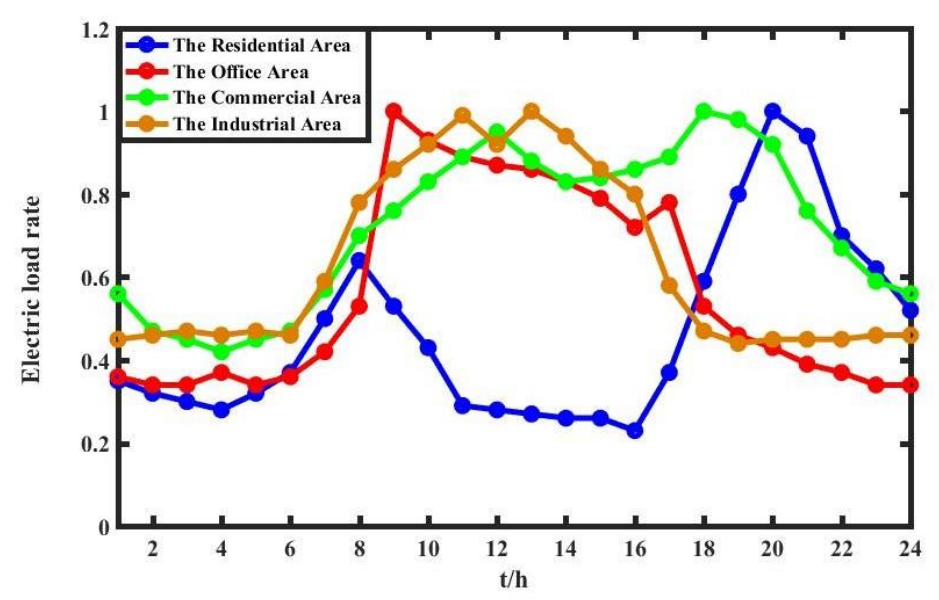

Figure 3. Typical electrical load rate curves of multiple functional areas.

It can be seen from Figure 3 that electric loads in the residential area show double peaks at 8 a.m. and 8 p.m., which are consistent with people's habits. From 8 a.m. to 9 a.m., the electric loads rise rapidly to the peak in the office area, and decrease significantly after work at 5 p.m. The peak period of electric loads in the commercial area are 8 a.m.-9 p.m., and the electric load rate is maintained above 0.65 . In periods other than business hours, the electric loads rate is maintained at a lower level. Compared with other functional areas, the industrial area has higher full-day load rate and load rate in the daytime is higher than that at night, which is consistent with the working systems of factories.

\subsubsection{Charging Loads of EVs}

The typical predicted charging loads curves of EVs of multiple functional areas are shown in Figure 4 , in which the number of EVs is assumed as 2000. The $x$-axis represents $24 \mathrm{~h}$ of the day. The Monte Carlo simulation method is adopted to simulate EVs parking, driving, and charging behavior at different times and different areas for predicting the spatiotemporal characteristics of charging loads of EVs [27].

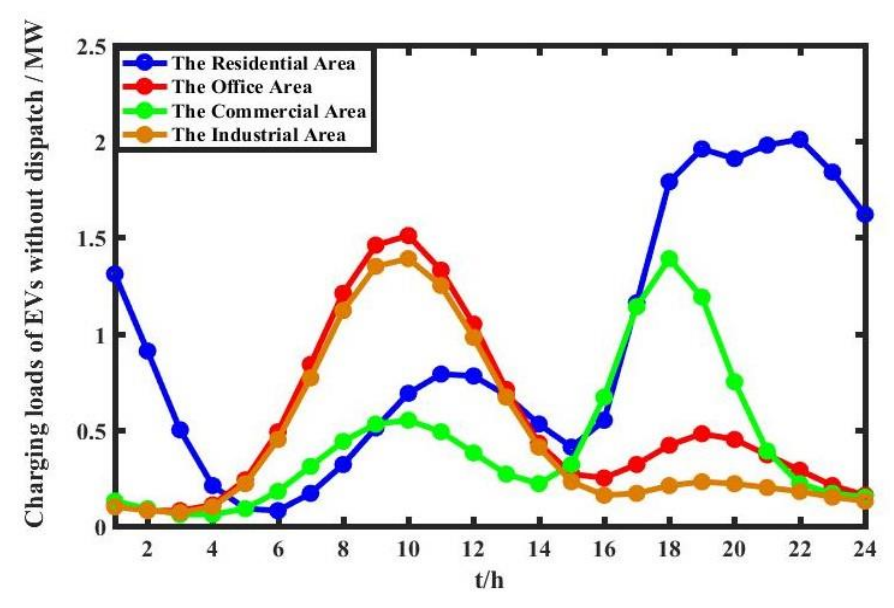

Figure 4. Predicted charging loads of EVs of multiple functional areas. 
It can be seen from Figure 4 that since residents in the residential area usually go out early and go home late, EVs are charged concentratively at night and the peak period of charging loads occur around 10 p.m. EVs in the office area are charged during working hours, usually from 8 a.m. to 5 p.m. The concentration period of load charging in the commercial area is generally 5 p.m.-9 p.m., and fast charging is taken due to the shorter parking time. Charging loads characteristics of the industrial area are similar to that of the office area, and are concentrated in the working hours from 8 a.m. to 5 p.m. for charging. However, the charging loads from 6 p.m. -9 p.m. in the industrial area are lower than that in the office area, because a small part of the office staff overworks. The number of EVs in the office area is higher than that of EVs in the industrial area during this period.

The peak of charging loads in each functional area overlaps with the peak period of electric loads of the functional area, but does not match the output curve of renewable energy in this functional area. It will not only impact the distribution network to a certain extent, but also is not conducive to the consumption of renewable energy. Thus, it is necessary to dispatch the charging loads of EVs which have flexibility and energy storage characteristics.

\subsubsection{Comparisons of the Load Characteristics of Multiple Functional Areas}

In summary, the load characteristics of multiple functional areas are summarized and compared in Table 3.

Table 3. Comparisons of load characteristics of multiple functional areas.

\begin{tabular}{lllll}
\hline \multicolumn{1}{c}{ Loads } & Residential Area & \multicolumn{1}{c}{ Office Area } & Commercial Area & \multicolumn{1}{c}{ Industrial Area } \\
\hline Heating Loads & $\begin{array}{l}\text { High at night and } \\
\text { low in the day, and } \\
\text { constrained by the } \\
\text { PMV index }\end{array}$ & $\begin{array}{l}\text { High during working } \\
\text { hours, low from the } \\
\text { end of work hours to } \\
\text { night, and constrained } \\
\text { by PMV index }\end{array}$ & $\begin{array}{l}\text { High during business } \\
\text { hours, low at night, } \\
\text { and constrained by } \\
\text { PMV index }\end{array}$ & $\begin{array}{l}\text { High during the } \\
\text { day, relatively low } \\
\text { at night, not subject } \\
\text { to PMV index }\end{array}$ \\
\hline Cooling Loads & $\begin{array}{l}\text { Affected by the } \\
\text { equivalent thermal } \\
\text { resistance } D\end{array}$ & N/A & N/A & $\begin{array}{l}\text { Affected by the } \\
\text { equivalent thermal } \\
\text { resistance } D\end{array}$ \\
\hline Electric Loads & $\begin{array}{l}\text { Double peaks in } \\
\text { the morning } \\
\text { and evening }\end{array}$ & $\begin{array}{l}\text { High during } \\
\text { working hours }\end{array}$ & $\begin{array}{l}\text { Double peaks at } \\
\text { noon and night }\end{array}$ & $\begin{array}{l}\text { High loads rate } \\
\text { throughout the day, } \\
\text { highest during } \\
\text { the daytime }\end{array}$ \\
\hline Charging Loads of EVs & $\begin{array}{l}\text { Concentrated on } \\
\text { charging at night }\end{array}$ & $\begin{array}{l}\text { Concentrated on } \\
\text { charging during } \\
\text { working hours }\end{array}$ & $\begin{array}{l}\text { Concentrated on } \\
\text { charging during } \\
\text { shopping and leisure } \\
\text { time, and with large } \\
\text { charging power }\end{array}$ & $\begin{array}{l}\text { Concentrated on } \\
\text { charging during } \\
\text { working hours }\end{array}$ \\
\hline
\end{tabular}

It can be seen from Table 3 that the heating loads, the cooling loads, the electric loads, and the charging loads of multiple functional areas have different characteristics. The functional areas could be connected through tie lines and the transferability of EVs to achieve complementary coordination and reduce the abandonment rate of renewable energy. The heating/cooling loads inside a functional area also have a certain flexibility and adjustability, which could be utilized to improve the consumption of renewable energy and suppress the volatility of renewable energy.

\section{Coordinated Dispatching Model of IESs Considering Differences of Multiple Functional Areas}

Previous work on IES system dispatching mainly focused on single-area IES. There are few studies on multiarea IES dispatching and less consideration on different load characteristics of different areas. Thus, inevitably, there were some problems, such as low energy efficiency and poor economic benefits. To solve the above problems, the different load characteristics of different functional areas are considered and the following points are proposed in this paper: (1) the cooling loads, heating loads, and charging loads of EVs have energy storage characteristics; (2) the cooling loads and heating loads 
are suitable for transmission within the functional areas; (3) the electric loads and charging loads of electric vehicles are suitable for transmission across functional areas. Thus, a coordinated dispatching model of IESs is established considering the above characteristics. Through the complementarity of various forms of energy systems and different loads in multiple functional areas, the absorption rate of renewable energy can be effectively improved and the economic efficiency of the operation of IESs can be improved.

Uncertainty is a key factor to be considered in power management and there is strong uncertainty in renewable energy output. Scenario analysis and robust optimization are commonly used to deal with uncertainty in power management problems. In scenario analysis, uncertainties are described through scenario sets [28]. Uncertain parameter intervals are used in robust optimization to describe the uncertainty. Robust optimization requires less information about the probability distribution of random variables [29-31]. Considering that scenario analysis can clearly describe the probability characteristics of uncertain variables and its optimization model can be easily calculated, scenario analysis is used to deal with production uncertainty in this paper. It is assumed that there are $S$ scenes, and the probability of scene $s$ is $p_{s}$. The lowest operating cost is generally taken as the objective of coordinated dispatching model. In order to promote the consumption of renewable energy, the cost of abandoned WT and PV power is added to the total operating cost of the IESs. Thus, the objective function of coordinated dispatching of IESs is to minimize the total operating cost of the systems, and can be represented as

$$
\begin{aligned}
& \min \sum_{s=1}^{S} p_{s} \sum_{t=1}^{T} \sum_{r=1}^{R}\left\{\sum_{i=1}^{N_{\text {rchp }}}\left[c_{i}^{\text {chp }}\left(P_{\text {chp }, r i, t,}^{s} H_{\text {chp }, r i, t}^{s}\right)+\rho_{1}\left|P_{\text {chp }, r, i, t}^{s}-P_{\text {chp }, r, i, t}^{0}\right|\right]+\varphi P_{\text {buy }, r, t}^{s}+\rho_{2}\left|P_{\text {buy }, r, t}^{s}-P_{\text {buy }, r, t}^{0}\right|+\rho_{3} P_{\text {cut }, r, t}^{s}\right\} \\
& c_{i}^{\operatorname{chp}}\left(P_{\text {chp }, r, i, t^{\prime}}^{s} H_{\text {chp }, r, i, t}^{s}\right)=a_{0, r, i}+a_{1, r, i} P_{\text {chp }, r, i, t}^{s}+a_{2, r, i} H_{\text {chp }, r, i, t}^{s}+a_{3, r, i}\left(P_{\text {chp }, r, i, t}^{s}\right)^{2} \\
& +a_{4, r, i}\left(H_{\text {chp }, r, i, t}^{s}\right)^{2}+a_{5, r, i} P_{\text {chp }, r, i, t}^{s} H_{\text {chp }, r, i, t}^{s} \\
& P_{\mathrm{cut}, r, t}^{s}=P_{\mathrm{PW}, r, t, \max }^{s}+P_{\mathrm{PV}, r, t, \max }^{s}-P_{\mathrm{PW}, r, t}^{s}-P_{\mathrm{PV}, r, t}^{s}-P_{\mathrm{PWH}, r, t}^{s}-P_{\mathrm{PVH}, r, t}^{s}
\end{aligned}
$$

The cost function of CHP units and the expression of abandoned WT and PV power could be described as (12) and (13), respectively.

The constraints of the subsystems in the IESs are as follows:

1. Constraints of electric systems

Constraint of the electric power balance [32] can be represented as

$$
\sum_{i=1}^{N_{\text {rchp }}} P_{\mathrm{chp}, r, i, t}^{s}+P_{\mathrm{buy}, r, t}^{s}+P_{\mathrm{PV}, r, t}^{s}+P_{\mathrm{PW}, r, t}^{s}+\sum_{l=1}^{L_{r}} P_{\mathrm{tie}, l, t}^{s}=P_{\mathrm{L}, r, t}^{s}+P_{\mathrm{ch}, r, t}^{s}+P_{\mathrm{EC}, r, t}^{s}
$$

It shows that electric loads can be balanced between functional areas through tie lines and EVs. Constraints of the CHP unit can be represented as

$$
\begin{gathered}
P_{\mathrm{chp}, r, i, t}^{s}=H_{\mathrm{chp}, r, i, t}^{s} / k_{\mathrm{hp}, r, i} \\
P_{\mathrm{chp}, r, i}^{\min } \leq P_{\mathrm{chp}, r, i, t}^{s} \leq P_{\mathrm{chp}, r, i}^{\max } \\
-U_{r, i}^{\max } \cdot \Delta t \leq P_{\mathrm{chp}, r, i, t+1}^{s}-P_{\mathrm{chp}, r, i, t}^{s} \leq U_{r, i}^{\max } \cdot \Delta t
\end{gathered}
$$

The thermoelectric constraint is described as (15), the electric output constraint is described as (16), and the climbing constraint is described as (17).

Constraints of the purchasing power can be represented as

$$
P_{r, t}^{s} \geq 0
$$


It means that electric power can be purchased but not sold.

Constraints of the WT and PV can be represented as

$$
\begin{gathered}
P_{\mathrm{PV}, r, t}^{s} \geq 0 \\
P_{\mathrm{PW}, r, t}^{s} \geq 0 \\
P_{\mathrm{PWH}, r, t}^{s} \geq 0 \\
P_{\mathrm{PVH}, r, t}^{s} \geq 0 \\
0 \leq P_{\mathrm{PV}, r, t}^{s}+P_{\mathrm{PWH}, r, t}^{s} \leq P_{\mathrm{PV}, r, t, \max }^{s} \\
0 \leq P_{\mathrm{PW}, r, t}^{s}+P_{\mathrm{PVH}, r, t}^{s} \leq P_{\mathrm{PW}, r, t, \max }^{s}
\end{gathered}
$$

Constraints of the tie line transmission power can be represented as

$$
-P_{\mathrm{tie}, l, t}^{\max } \leq P_{\mathrm{tie}, l, t}^{\mathrm{s}} \leq P_{\mathrm{tie}, l, t}^{\max }
$$

2. Constraints of heating systems

Constraints of the electric boiler can be represented as

$$
\begin{gathered}
P_{\mathrm{EB}, r, t}^{s}=P_{\mathrm{PWH}, r, t}^{s}+P_{\mathrm{PVH}, r, t}^{s} \\
H_{\mathrm{EB}, r, t}^{s}=\eta_{\mathrm{EB}, r} P_{\mathrm{EB}, r, t}^{s} \\
0 \leq H_{\mathrm{EB}, r, t}^{s} \leq H_{\mathrm{EB}, r}^{\max }
\end{gathered}
$$

In order to improve the consumption rate of renewable energy, it is assumed that the electric boiler is installed in the generating stations of renewable energy, and the electric energy required by the electric boiler can only supplied by the renewable energy connected to it. It is ensured by (26) that the electric boiler in area $r$ consumes WT and PV power in area $r$ only. Constraints of thermoelectric conversion relations and heating output limits of the electric boiler are described in (27) and (28), respectively.

For areas where the heating loads are the ordinary heating loads, i.e., residential, office, or commercial areas, the constraints can be represented as

$$
\begin{gathered}
\sum_{i=1}^{N_{r c h p}} H_{\mathrm{chp}, r, i, t}^{s}+H_{\mathrm{EB}, r, t}^{s}=H_{\mathrm{L}, r, t}^{s} \\
H_{\mathrm{L}, r, t}^{s}=\chi_{r}^{s}\left(T_{\mathrm{g}, r, t}^{s}-T_{\mathrm{h}, r, t}^{s}\right) \\
T_{\mathrm{h}, r, t}^{s} \leq T_{\mathrm{g}, r, t}^{s} \leq T_{\mathrm{g}, r, \max }^{s} \\
-\sigma_{r, t}^{s} \leq \lambda_{r, P M V, t}^{s} \leq+\sigma_{r, t}^{s}
\end{gathered}
$$

For areas with the productive heating loads, i.e., the industrial area, the constraints are presented in (4) and (5).

3. Constraints of cooling systems

Constraints of indoor cooling can be represented as

$$
Q_{\mathrm{EC}, r, t}^{s}=Q_{\mathrm{L}, r, t}^{s}
$$




$$
\widetilde{T}_{\mathrm{n}, r, \min }^{s} \leq \widetilde{T}_{\mathrm{n}, r}^{s} \leq \widetilde{T}_{\mathrm{n}, r, \max }^{s}
$$

The indoor cooling constraints also include the ETP model described in (6).

Constraints of the electric refrigerator can be represented by

$$
\begin{gathered}
Q_{\mathrm{EC}, r, t}^{s}=P_{\mathrm{EC}, r, t}^{s} \eta_{\mathrm{EC}, \mathrm{r}} \\
Q_{\mathrm{EC}, r, \text { min }}^{s} \leq Q_{\mathrm{EC}, r, t}^{s} \leq Q_{\mathrm{EC}, r, \text { max }}^{s}
\end{gathered}
$$

The proposed coordinated dispatching model of IESs considering differences of multiple functional areas is established using the programming software YALMIP in MATLAB, and is then solved by the commercial optimization solver CPLEX 12.6.1.

The objective function of the proposed model is a quadratic function and the constraints are linear functions, so it is a quadratic programming problem. YALMIP is a free MATLAB toolbox which can solve many optimization models, such as quadratic programming, second-order cone programming, and mixed integer programming. The greatest feature of YALMIP is that it can integrate many external optimization solvers regardless of whether these solvers are written in MATLAB or not.

CPLEX is a commercial optimization solver developed by IBM. It is specifically used to solve four basic problems: large-scale linear programming, quadratic programming, constrained quadratic programming, second-order cone programming, and corresponding mixed integer programming. CPLEX can solve some very difficult industry problems and its solving speed is very fast. With the support of CPLEX, the efficiency of MATLAB for large-scale problems and linear programming has been greatly improved.

The process of the optimization algorithm is shown in Figure 5.

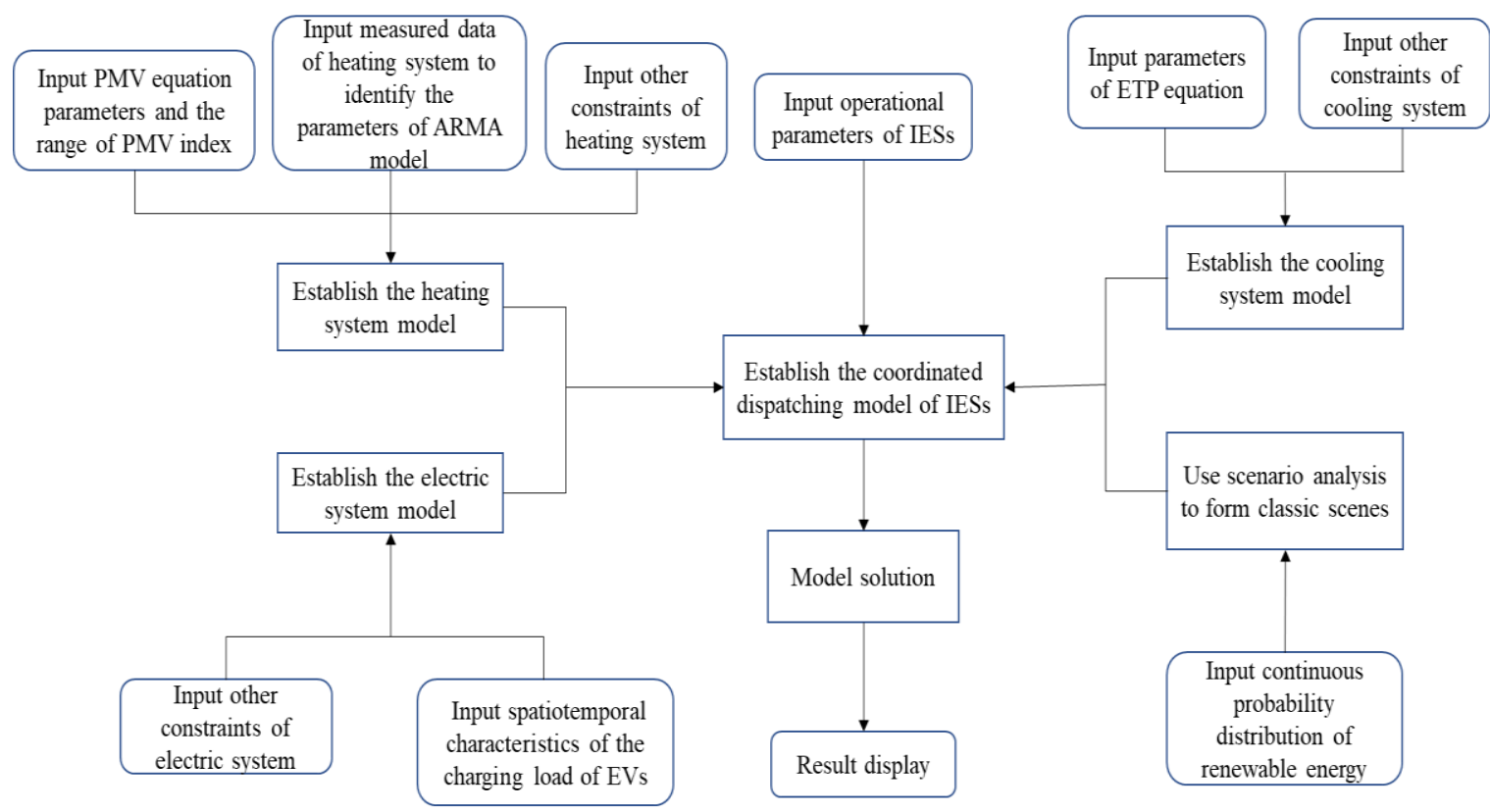

Figure 5. The process of the optimization algorithm.

\section{Case Studies}

Renewable energy is developing rapidly in Europe, and its installed proportion is relatively high. In view of the uncertainties and fluctuations of renewable energy and the reduction of fossil fuel power generation, Denmark has attached great importance to the development and promotion of commercially available and scalable high-performance distributed electrothermal energy systems in recent years. At present, the energy supply of Denmark mainly comes from green energy sources such as wind energy, biomass energy, and solar energy. Denmark pays attention to the interaction and 
complementarity between green renewable energy and energy storage systems, and combines solar, wind, and biomass energy with electric and thermal energy storage to make the whole energy system more flexible.

Taking Svendborg, Denmark as an example, there are currently three solar power stations in Svendborg. One of them has an area of $6000 \mathrm{~m}^{2}$ and annual power supply of $2736 \mathrm{MWh}$. "Waste incineration and electrothermal energy storage" is one of the main sources of thermal energy supply in Svendborg at present. Local waste incinerators burn about 70,000 tons of waste annually, including food packaging, cartons, and plastics. By using the latest technology, the combustion efficiency is up to $98 \%$. The incinerator burns at a stable high temperature of $1000{ }^{\circ} \mathrm{C}$, which reduces the emission of harmful gases such as $\mathrm{CO}_{2}$. Through the complementary use of various forms of energy systems, the power generation efficiency of Svendborg has reached $49 \%$.

For demonstrating the effectiveness of the proposed coordinated dispatching model of IESs, an actual distribution system in Jianshan District, Haining, Zhejiang Province of China is presented. Due to many factors, such as renewable energy power generation subsidy policy, local photovoltaic panel capacity, and the effect of the demonstration zone, the installed capacity of renewable energy in Jianshan District has increased rapidly. By August 2018, the total installed capacities of grid-connected PV and WT in Jianshan District were $180 \mathrm{MW}$ and $50 \mathrm{MW}$, respectively, which are expected to continue growing in the next several years. The high penetration rate of renewable energy leads to the great operating pressure for the dispatchers of the distribution network in the region. When the loads are low, the excess energy is evenly transferred to the transmission systems with high-voltage level. Taking one typical daily electrical load curve and the typical photovoltaic output data as example, the PV output can be considered as a negative load. Then, the loads with different output ratios of PV are shown in Figure 6.

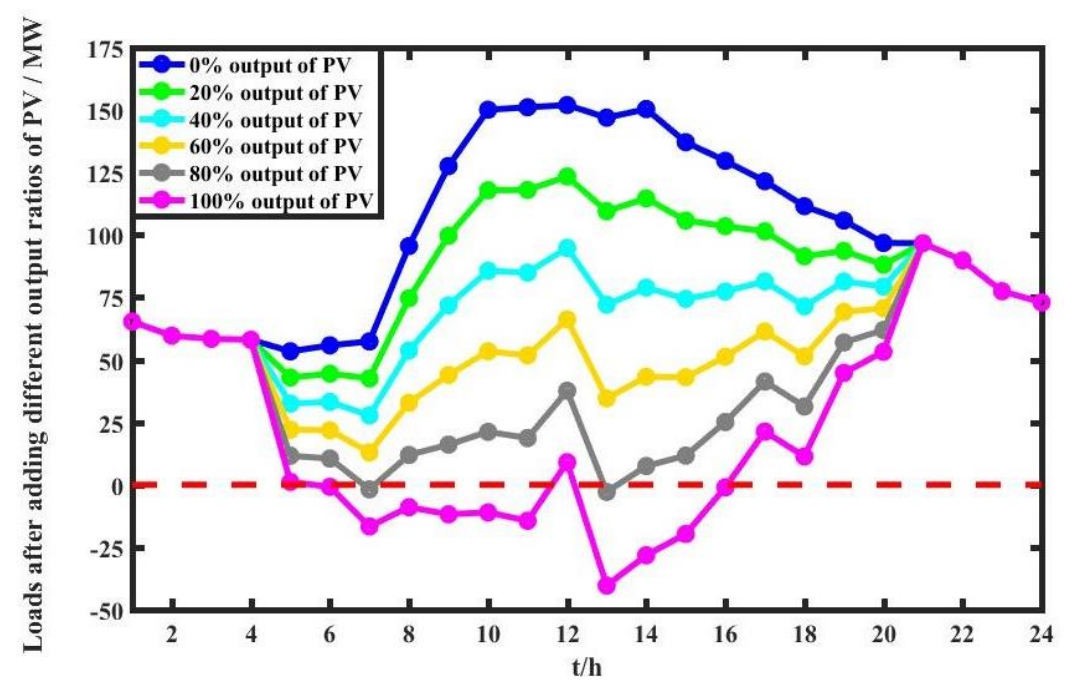

Figure 6. Loads after adding different PV output ratios.

It can be seen from Figure 6 that when the output ratio of PV is more than $80 \%$, the loads after adding the output of PV are less than 0 . In order to improve the power grid structure and utilize the distribution network to transfer the excess energy, the measures to be taken in Jianshan District include improving the interconnection level of distribution networks and building energy storage devices. In 2016, Zhejiang Development Planning and Research Institute issued the "Central Heating Plan of Haining", which proposed to implement centralized heating in Haining. At the same time, Jianshan District has been clearly divided into four functional areas in the planning stage, and the development of EVs is encouraged. Under this background, the effect of coordinated dispatching of IESs considering the differences of multiple functional areas on renewable energy consumption in Jianshan District is analyzed. 
The geographical distribution of functional areas in Jianshan District is shown in Figure 7 , where areas 1,2,3, and 4 represent the residential area, the office area, the commercial area, and the industrial area, respectively. The connection between functional areas is through tie lines $1-2,1-3$, and $1-4$, respectively. The positive direction of power flow in the tie line is shown by the arrows in Figure 7.

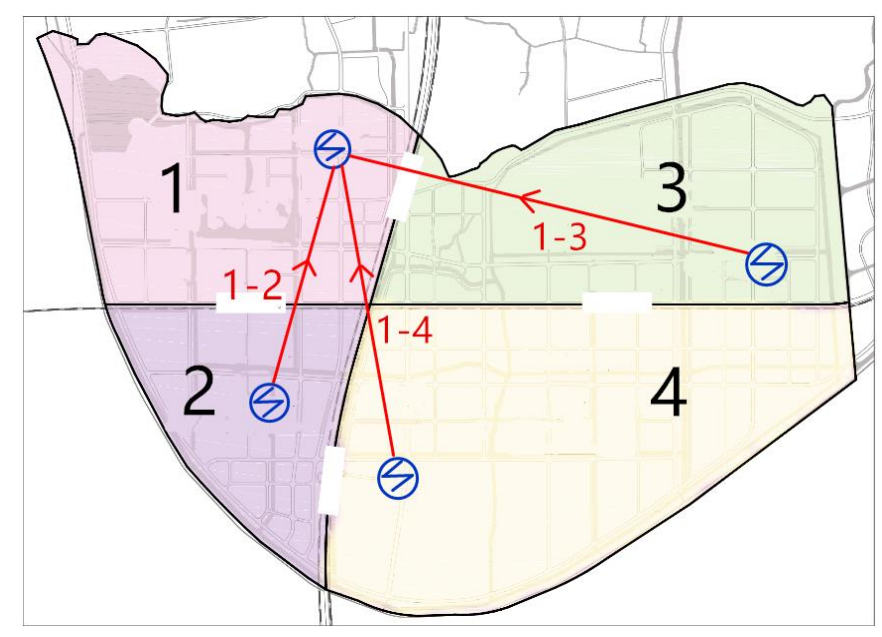

Figure 7. Geographical distribution of functional areas in Jianshan District.

The relevant parameters of the case are listed in the Appendix A. The power capacity of each functional area is shown in Table A1. The parameters of CHP units are shown in Table A2. It is assumed that there is only one CHP unit in each functional area. The parameters of EVs are shown in Table A3. The operating parameters of the IES are shown in Table A4. The parameters of the PMV index are shown in Table A5. The coefficients of the ARMA model of heating systems are shown in Table A6. The initial values of the heating/cooling systems are shown in Table A7. It is assumed that the heating systems of each functional area have the same initial value of operation. The typical daily loads and outdoor temperature data of each functional area in winter are shown in Table A8. The continuous probability distribution of unit WT and PV is shown in Table A9.

\subsection{The Optimization Results of Coordinated Dispatching for an Integrated Energy System}

The population of Jianshan District is about 100,000, and the penetration rate of EVs is taken as $2 \%$, that is, the number of EVs is 2000; the charging coefficient $\alpha_{r, k}^{\min }$ is taken as 0.7 , the PMV index is taken as 0.5 , the adjustable heating duration $T^{\prime}$ is taken as 3 , the capacity of each tie line is taken as $5 \mathrm{MW}$, and the equivalent thermal resistance $D$ is taken as 2 . Thus, the optimization of coordinated dispatching for the integrated energy system can be performed.

The correlation between the output of renewable energy and the charging power of EVs in each functional area is analyzed, and the results are shown in Table 4.

Table 4. Correlation coefficients between the output of renewable energy and the charging power of EVs in each functional area.

\begin{tabular}{ccccc}
\hline Time Period & $\begin{array}{c}\text { Residential } \\
\text { Area }\end{array}$ & Office Area & $\begin{array}{c}\text { Commercial } \\
\text { Area }\end{array}$ & Industrial Area \\
\hline 8 a.m.-5 p.m. & 0.7411 & 0.6709 & 0.5345 & 0.6548 \\
6 p.m.-9 p.m. & 0.7642 & 0.4455 & 0.5482 & 0.7979 \\
10 p.m.-7 a.m. & 0.6885 & N/A & N/A & 0.7447 \\
\hline
\end{tabular}

It can be seen from Table 4 that the correlation coefficient between the output of renewable energy and the charging power of EVs in each functional area is positive, indicating that the charging 
power of EVs and the output of renewable energy are synchronously changed. The larger the output of renewable energy, the larger the charging power of EVs will become, which provides a larger consumption margin for renewable energy. Thus, the correlation coefficient in the area with rich renewable energy, such as the residential area and the industrial area, is also significantly larger. During 10 p.m. -7 a.m., the correlation coefficient and the output of renewable energy in the industrial area is the largest, but EVs are concentrated in the residential area. In order to increase the consumption rate of the renewable energy in the industrial area during this period, it is possible to reduce the charging price of the industrial area during this period so that more EVs could be charged in this area. During 6 p.m. -9 p.m., EVs are concentrated in the commercial area, but the correlation coefficient is small. This is because the parking time of EVs in this time period is short, and in this short parking time, the owners of EVs prefer to utilize the fast charging mode to meet their charging requirements, rather than responding to dispatching instructions to consume excess renewable energy. Thus, the commercial area should not set too many charging piles, and it is better to transfer this part of the charging demand to other periods or other areas.

For analyzing the optimization of electric power and tie line power in a certain scene, the residential area is taken as an example for demonstration, and the result is shown in Figure 8. The equivalent electric loads are the electric loads superimposed with the charging loads of EVs. It can be seen from Figure 8 that since PV power is the major renewable energy in the residential area and the loads of the daytime are low, the renewable energy is excessive in the daytime, and it should be transmitted through three tie lines. There is abandoned WT and PV power at 2 p.m., 4 p.m., and 5 p.m. This is because the three tie lines connected to the residential area have reached the limitation of transmission.

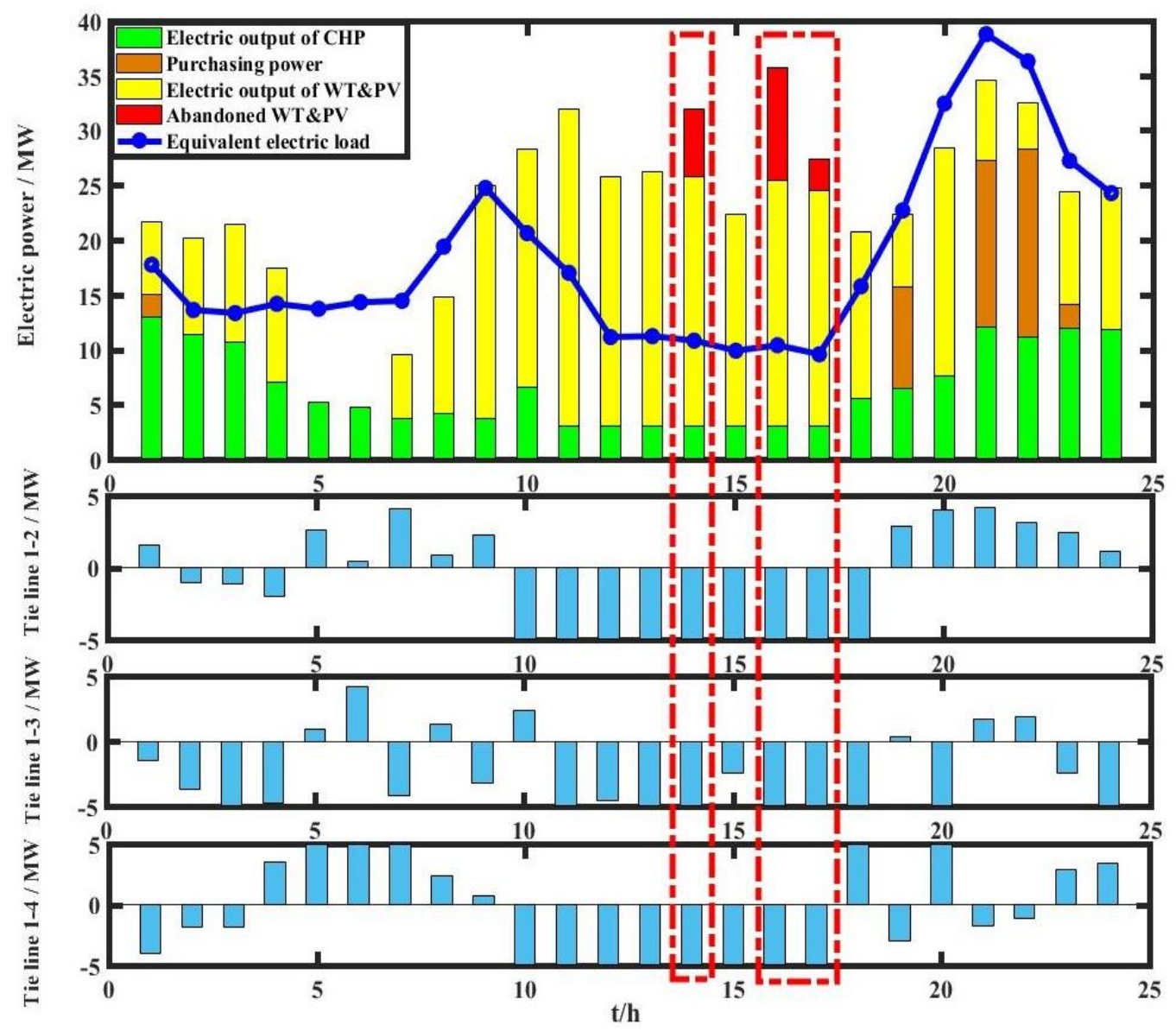

Figure 8. The optimization of electric power and tie line power in the residential area. 
Furthermore, the industrial area is also taken as an example for analyzing the optimization of the cooling power, the heating power, the electric power, and the tie line power, which is shown in Figure 9. The equivalent electrical loads are the electric loads superimposed with the charging loads of EVs. It can be seen from Figure 9 that there is abandoned WT and PV power at 5 a.m. and 8 p.m. During this period, the CHP unit has reached its minimum technical output, providing the largest consumption margin of renewable energy. Meanwhile, the heating power is $31.77 \mathrm{MW}$ and $32.17 \mathrm{MW}$ at $5 \mathrm{a} . \mathrm{m}$. and 8 p.m., respectively. The heating load is $30.15 \mathrm{MW}$ and $30.55 \mathrm{MW}$ at 5 a.m. and 8 p.m., respectively. The heating power has exceeded the heating load in the allowable range of the heat elasticity at 5 a.m. and 8 p.m. to consume more renewable energy. The cooling power during this period is larger than the adjacent periods, and the indoor temperature of the cooling building has reached $-20^{\circ} \mathrm{C}$, which is the lowest temperature in allowance. The tie line has also reached the limitation of the transmission power. The abandonment rate of WT and PV power has been minimized through the coordination optimization of cooling power, heating power, electric power, and tie line power.

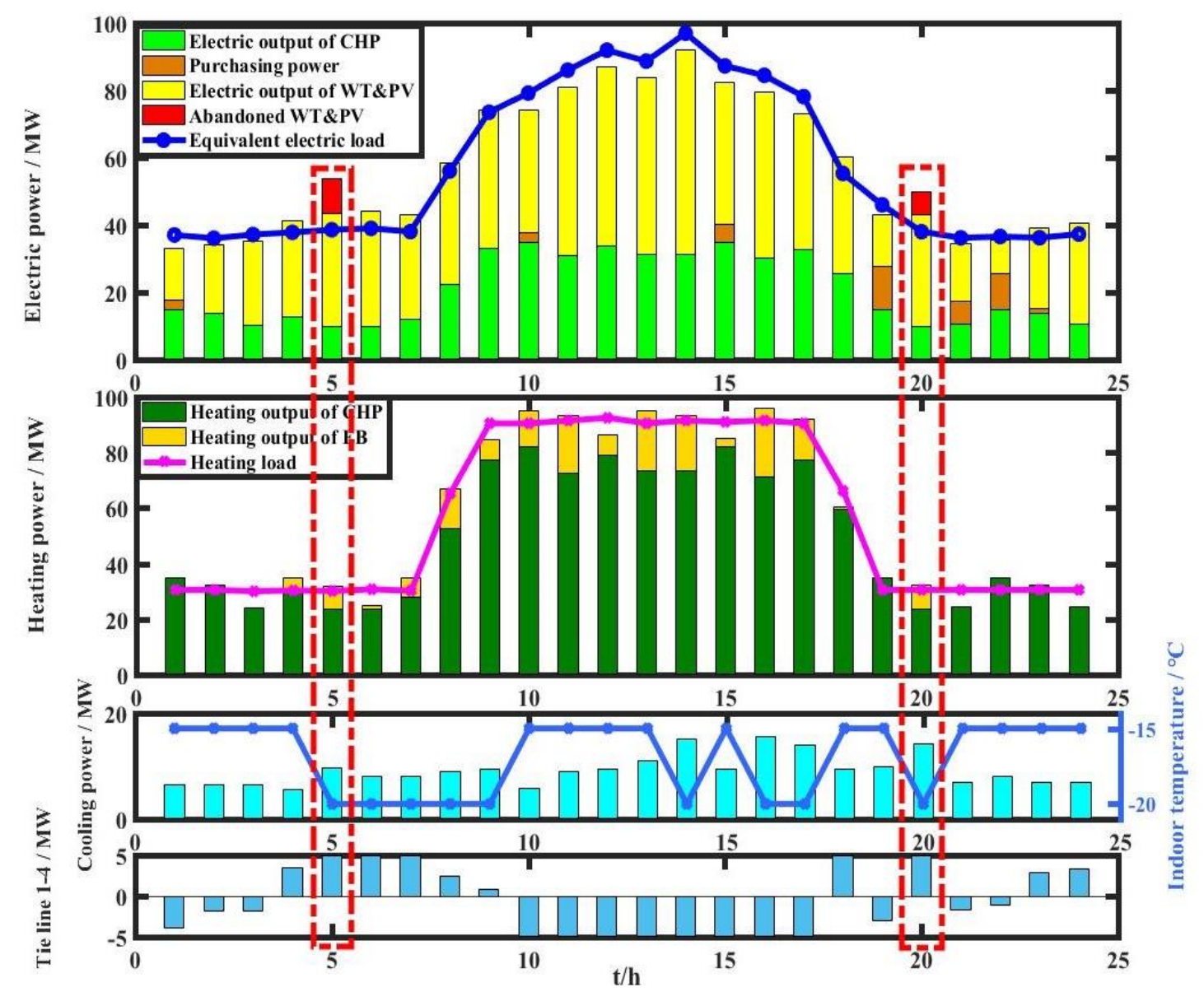

Figure 9. The optimization of cooling power, heating power, electric power, and tie line power in the industrial area.

\subsection{The Impacts of the Penetration Rate of EVs and the Charging Coefficient on the Consumption of Renewable Energy}

The impacts of the penetration rate of EVs on the consumption of renewable energy are compared and analyzed, and the results for different penetration rates of EVs are shown in Table 5. Since there is no abandoned WT and PV power in both the office area and the commercial area, only abandoned WT and PV power in the residential area and the industrial area are listed. It can be seen from Table 5 that the abandoned WT and PV power in the residential area and the industrial area are also decreasing with the increase of the penetration rate of EVs, while the reduction of the residential area is more 
obvious. The reason is that the number of EVs distributed in the residential area is greater than the industrial area during the periods of abandoned WT and PV power, so the penetration rate of EVs have a greater impact on the consumption of renewable energy in the residential area than in the industrial area. In summary, transferring the charging loads of EVs in the industrial area to the periods with abandoned WT and PV power by reducing the charging price in these periods should be considered.

Table 5. Abandoned WT and PV power in functional areas under different penetration rates of EVs.

\begin{tabular}{ccc}
\hline $\begin{array}{c}\text { Penetration Rate } \\
\text { of EVs }\end{array}$ & $\begin{array}{c}\text { Abandoned WT and PV power } \\
\text { in Residential Area/(MW) }\end{array}$ & $\begin{array}{c}\text { Abandoned WT and PV power } \\
\text { in Industrial Area/(MW) }\end{array}$ \\
\hline $2 \%$ & 12.73 & 18.37 \\
$6 \%$ & 9.66 & 15.63 \\
$10 \%$ & 6.88 & 14.29 \\
\hline
\end{tabular}

The impacts of the charging coefficient $\alpha_{r, k}^{\min }$ on the consumption of renewable energy are compared and analyzed, and the results for different charging coefficients are shown in Table 6 . Since there is no abandoned WT and PV power in both the office area and the commercial area, only abandoned WT and PV power in the residential area and the industrial area is listed in Table 6 . It can be seen from Table 6 that with the decrease of $\alpha_{r, k}^{\min }$, the abandoned WT and PV power in the residential area and the industrial area is also decreasing, because $\alpha_{r, k}^{\min }$ relates to the minimum charging power in time period $k$ of area $r$. When $\alpha_{r, k}^{\min }$ decreases, the lower limit of charging power could be more relaxed, which means that EVs can be charged in other time periods and other areas. Thus, the charging power of EVs could match the output curves of renewable energy better, and the abandoned power of renewable energy could be reduced.

Table 6. Abandoned WT and PV power in functional areas under different charging coefficients.

\begin{tabular}{ccc}
\hline $\boldsymbol{\alpha}_{r, k}^{\min }$ & $\begin{array}{c}\text { Abandoned WT and PV power } \\
\text { in Residential Area/(MW) }\end{array}$ & $\begin{array}{c}\text { Abandoned WT and PV power } \\
\text { in Industrial Area/(MW) }\end{array}$ \\
\hline 0.7 & 12.73 & 18.37 \\
0.4 & 11.03 & 17.95 \\
0 & 10.88 & 17.67 \\
\hline
\end{tabular}

\subsection{The Impacts of the Capacity of Each Tie Line on the Consumption of Renewable Energy}

The impacts of tie line capacity on the consumption of renewable energy are compared and analyzed in Table 7. Since there is no abandoned WT and PV power in both the office area and the commercial area in various situations, only abandoned WT and PV power in the residential area and the industrial area is listed in Table 7. It can be seen from Table 7 that when the tie line capacity is increased, the abandoned WT and PV power in the residential area and the industrial area is decreasing, while the reduction of the residential area is more obvious. Because the electric loads and the heating loads of the residential area are not high during the daytime, the output of PV in the residential area is relatively high during this period, and the excess power of PV could be transmitted to other functional areas where the electric loads and heating loads are relatively high through the three tie lines. Therefore, the consumption rate of renewable energy in the residential area has been significantly improved with the increase of the capacity of tie lines. 
Table 7. Abandoned WT and PV power in functional areas under different tie line capacities.

\begin{tabular}{ccc}
\hline $\begin{array}{c}\text { Capacity of Each } \\
\text { Tie Line/(MW) }\end{array}$ & $\begin{array}{c}\text { Abandoned WT and PV power } \\
\text { in Residential Area/(MW) }\end{array}$ & $\begin{array}{c}\text { Abandoned WT and PV power } \\
\text { in Industrial Area/(MW) }\end{array}$ \\
\hline 5 & 12.73 & 18.37 \\
8 & 1.58 & 11.28 \\
10 & 0 & 7.54 \\
\hline
\end{tabular}

There is abandoned WT and PV power during 5 a.m.-7 a.m. in the industrial area, and the electric loads, the heating loads, and the cooling loads of other functional areas are not high and the output of renewable energy of other functional areas is rich during this period. Meanwhile, there is only one tie line in the industrial area, so the renewable energy cannot be completely consumed through the tie line. In summary, the tie line capacity of the industrial area could be expanded or tie lines between the industrial area and other functional areas could be established to reduce the abandonment of WT and PV power in the industrial area.

\subsection{The Impacts of the PMV Index and the Adjustable Heating Duration on Heating Systems}

The impacts of the PMV index on heating systems are compared and analyzed in Table 8. Since the PMV index is not suitable for evaluating the heating loads of the industrial area and there is no abandoned WT and PV power in the commercial area, only the abandoned WT and PV power in the residential area and the office area are listed in Table 8. Taking the residential area as an example, the heating loads curves and indoor temperature curves under different PMV indices are shown in Figure 10.
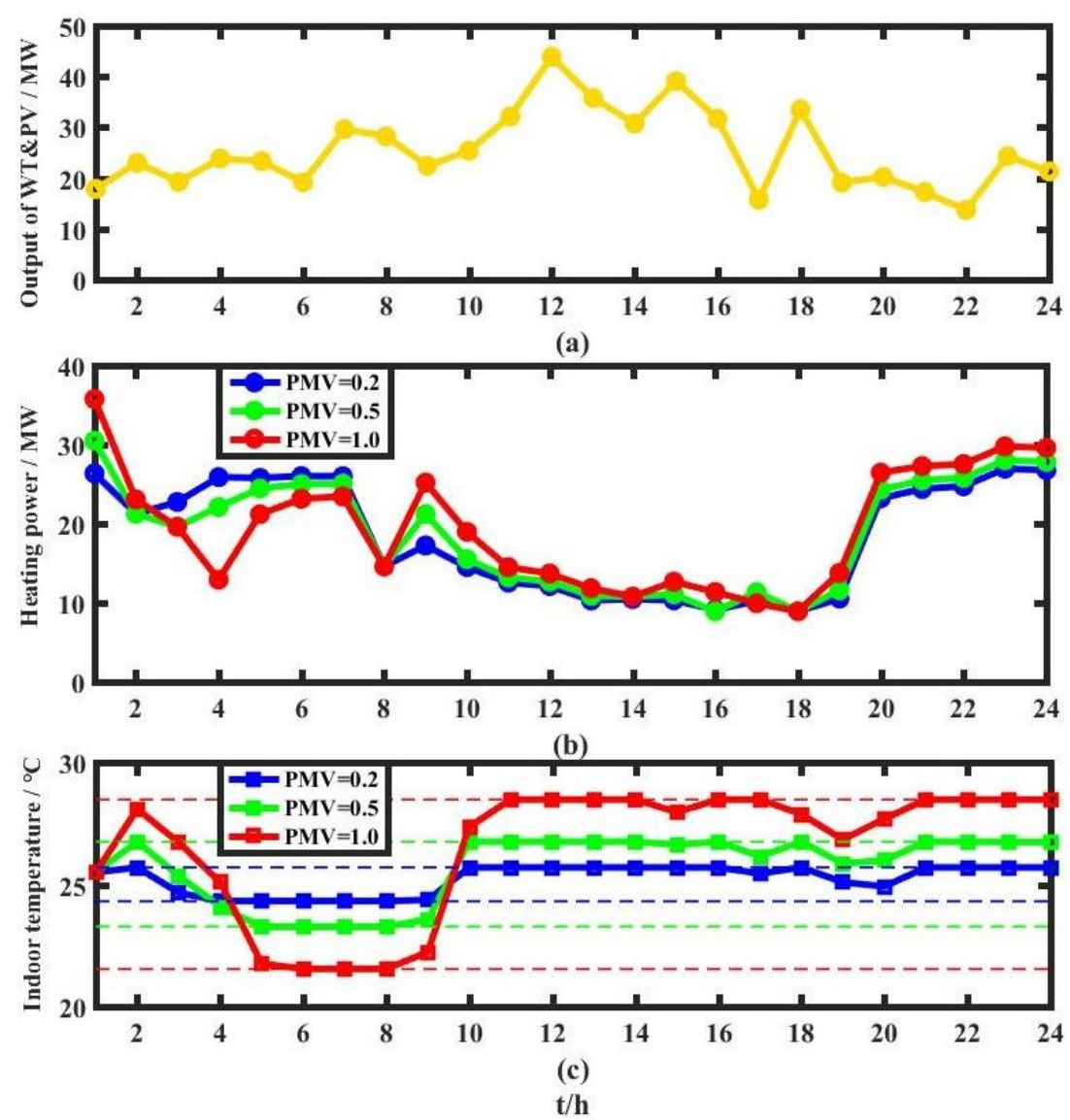

Figure 10. Impacts of the PMV index on heating systems. 
Table 8. Abandoned WT and PV power in functional areas under different PMV indexes.

\begin{tabular}{ccc}
\hline PMV Index & $\begin{array}{c}\text { Abandoned WT and PV power } \\
\text { in Residential Area/(MW) }\end{array}$ & $\begin{array}{c}\text { Abandoned WT and PV power } \\
\text { in Office Area/(MW) }\end{array}$ \\
\hline 0.2 & 13.68 & 0.75 \\
0.5 & 12.73 & 0 \\
1 & 2.20 & 0 \\
\hline
\end{tabular}

Figure 10a shows the output curve of WT and PV power of the residential area in a specific scenario. Figure $10 \mathrm{~b}, \mathrm{c}$ show the heating loads power curves and the indoor temperature curves of the heating building under different PMV index in this scene, respectively. The dotted lines in Figure 10c are the allowed range of indoor temperature fluctuations under the corresponding PMV index. It can be seen from Table 8 that as the PMV index becomes stricter, the abandoned WT and PV power in the residential area increases and there is abandoned WT and PV power in the office area when the PMV index is 0.2. This is because the stricter the PMV limit is, the smaller the range of indoor temperature fluctuations, and the smaller the elasticity of the heating loads on the amplitude axis is, resulting in a reduction in the virtual 'heat storage' capacity of the heating systems. Therefore, in the case of large fluctuations in renewable energy, it cannot work well to stabilize and consume renewable energy. In the residential area, the output of WT and PV is large during 8 a.m. -5 p.m. and abandoned WT and PV power appears during this period. When the PMV index is widened, the heating loads during this period can be increased and the indoor temperature is increased to the upper limit within the allowed range, thus allowing consumption of renewable energy. In summary, the restriction of the PMV index could be relaxed to reduce the abandonment rate of $\mathrm{WT}$ and PV.

As for the industrial area, some industries could adjust their working time to alter the heating duration $T^{\prime}$ across a wider time range. The impacts of $T^{\prime}$ on the consumption of renewable energy are compared and analyzed in Table 9. It can be seen from Table 9 that when $T^{\prime}$ is increased, the abandoned WT and PV power of the industrial area decreases. Therefore, if heating supply could be adjusted at a larger time scale, more renewable energy could be consumed.

Table 9. Abandoned WT and PV power in the industrial area under different adjustable heating durations.

\begin{tabular}{cc}
\hline$T^{\prime}$ & $\begin{array}{c}\text { Abandoned WT and PV power } \\
\text { in Industrial Area/(MW) }\end{array}$ \\
\hline 3 & 18.37 \\
6 & 15.32 \\
9 & 12.14 \\
\hline
\end{tabular}

\subsection{The Impacts of Equivalent Thermal Resistance on Cooling Systems}

The impacts of the equivalent thermal resistance $D$ on cooling systems are analyzed. According to the characteristics of different cooling buildings, the equivalent thermal resistance $D$ is taken as 1 and 3 , respectively. Taking the industrial area as an example, the cooling load curves and indoor temperature curves under different equivalent thermal resistance $D$ are demonstrated in Figure 11. The correlation coefficients between the output of renewable energy and the cooling power under different equivalent thermal resistance are shown in Table 10. 

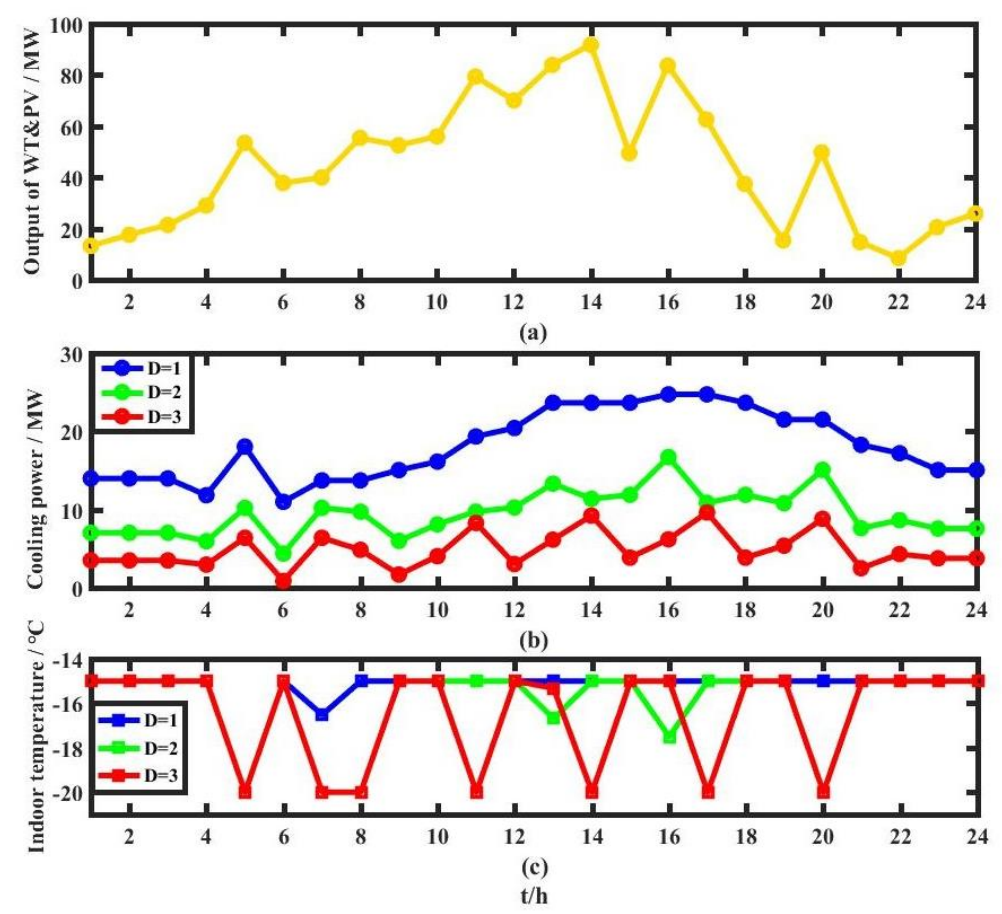

Figure 11. Impacts of the equivalent thermal resistance $D$ on cooling systems.

Table 10. Correlation coefficients between the output of renewable energy and the cooling power.

\begin{tabular}{cc}
\hline $\boldsymbol{D}$ & Correlation Coefficient \\
\hline 1 & 0.5585 \\
2 & 0.5741 \\
3 & 0.6237 \\
\hline
\end{tabular}

Figure 11a shows the output curve of WT and PV of the industrial area in a certain scenario. Figures $11 \mathrm{~b}$ and $11 \mathrm{c}$ show the cooling loads curves and the indoor temperature curves of the cooling building under different equivalent thermal resistances $D$ in this scene, respectively. The value of $D$ represents the degree of the influence of the indoor temperature in the previous period on the indoor temperature in the latter period. It can be seen from Figure $11 \mathrm{~b}$ that the larger $D$ is, the better the effect of the cooling systems on the cold energy storage is and the smaller the required cooling loads are. As shown in Figure 11c, when $D$ is larger, the cooling systems are more inclined to lower the indoor temperature, and the cold inertia is utilized to 'store energy'; when $D$ is smaller, the cooling systems are more inclined to just meet the cooling temperature requirements. It can be seen from Figure 11 and Table 10 that when $D$ becomes larger, the change of the cooling load is more synchronized with the changes of WT and PV. In summary, cooling buildings with a larger equivalent thermal resistance $D$ could be utilized to reduce the volatility of renewable energy.

\section{Conclusions}

Different characteristics of the cooling loads, heating loads, electric loads, and charging loads of EVs of multiple functional areas are analyzed. Then, a coordinated dispatching strategy for integrated energy systems considering the differences of multiple functional areas and various forms of energy systems is presented, in which the connection between the functional areas is established through tie lines and EVs. The balance of the cooling loads and the heating loads is realized within each functional area. In the proposed coordinated dispatching strategy, the elasticity and inertia of heating/cooling load are also considered to exert the energy storage function of the heating/cooling loads. Moreover, the impacts of these factors on the consumption of renewable energy and the suppression of the 
volatility of renewable energy are given. Finally, an actual distribution system in Jianshan District, Haining, Zhejiang Province of China was used to demonstrate the effectiveness of the proposed coordinated dispatching model of integrated energy systems. The simulation results show that it is conducive to consuming the excess renewable energy and suppressing the volatility of renewable energy by improving the penetration rate of EVs, tie line capacity, equivalent thermal resistance, and adjustable heating duration, and properly releasing the PMV restriction and the charging power restriction of EVs.

It should be mentioned that the model of this paper could be further studied under the following conditions: (1) A more detailed model of the heating network could be considered, including heating delay and loss, etc.; (2) The cost of tie lines could be considered to find the most suitable tie line capacity; (3) The distribution characteristics of EVs in various functional areas could be changed through the factor of electricity price to achieve more optimized dispatching without improving the penetration rate of EVs.

Author Contributions: L.L. and L.Y. conceptualized the study; L.Y., L.L., W.J. and M.S. performed the analysis; L.W. and C.Z. performed investigations; F.C. and L.W. acquired resources; F.C., L.W. and C.Z. acquired funding; L.L. wrote the original draft; H.X., Y.L. and T.Z. reviewed and edited the manuscript.

Funding: This research was funded by Science and Technology Foundation of SGCC (5211JY17000L), National Natural Science Foundation of China (51777185) and Natural Science Foundation of Zhejiang Province (LY17E070003).

Acknowledgments: This work is supported by Science and Technology Foundation of SGCC (5211JY17000L), National Natural Science Foundation of China (51777185) and Natural Science Foundation of Zhejiang Province (LY17E070003).

Conflicts of Interest: The authors declare no conflict of interest.

\section{Nomenclature}

(1) Indices and Sets$$
\text { i }
$$$$
j
$$

$k$

$r$

(2) Parameters

$a_{0, r, i}, a_{1, r, i}$,
$a_{2, r, i}, a_{3, r, i}$,
$a_{4, r, i}, a_{5, r, i}$
$C$
$E_{r, k}^{a v}$
$f_{\mathrm{cl}}$
$H_{\mathrm{EB}, r}^{\max }$
$h_{\mathrm{c}}$
$k_{\mathrm{hp}, r, i}$
$M_{\mathrm{Mh}, r, t}$
$N_{r c h p}$
$P_{\mathrm{a}}$
$P_{\mathrm{chin}, r, t^{\prime}} P_{\mathrm{ch}, r, t}$
$P_{\mathrm{max}}^{0}$

Index for CHP units. Index for magnitude of the thermal inertia of heating systems.

Index for time periods.

Index for functional areas.

Cost coefficients of CHP unit.

Equivalent heat capacity.

Average charging capacity of EVs in time period $k$.

Ratio of the area covered by the

clothes to the exposed area of the human body.

Maximum heating output of the electric boiler.

Surface heat transfer coefficient.

Heat-to-electric ratio of CHP unit.

Energy metabolism rate of the human body.

The number of CHP units in area $r$.

Partial pressure of water vapor of the air around the human body.

The lower and upper limits of the charging power of EVs.

Predicted charging power of EVs.
$S$

$t$

$L_{r}$

$T_{\mathrm{g}, r, \max }^{\mathrm{S}}$

$T_{\mathrm{g}, t}$

$T_{\mathrm{w}, t}, \widetilde{T}_{\mathrm{w}, t}$

$t_{\mathrm{b}}$

$t_{\mathrm{cl}}$

$U_{r, i}^{\max }$

W

$\alpha_{r, k}^{\min }$,

$\alpha_{r, k}^{\max }$

$\lambda$

$\sigma_{r, t}^{S}$

$\eta_{\mathrm{EC}, \mathrm{r}}$

$\eta_{\mathrm{ch}}$
Index for scenarios.

Index for operation time stages.

Sets of tie lines between area $r$ and other areas.

Maximum supply water temperature.

Water supply temperature of the heating network.

Outdoor temperature of the heating

buildings and the cooling buildings.

Average radiant temperature.

Garment outer surface temperature.

Maximum power regulation per unit time of CHP unit.

Mechanical power of the human body.

Lower and upper limits of the

charging coefficient.

Charging demand factor.

Range of the PMV index.

Conversion efficiency of the

electric refrigerator.

Charging efficiency of EVs. 


\begin{tabular}{|c|c|c|c|}
\hline$P_{\text {chp }, r, i^{\prime}}^{\min } P_{\text {chp }, r, i}^{\max }$ & $\begin{array}{l}\text { Lower and upper limit of electric } \\
\text { output of CHP unit. }\end{array}$ & $\eta_{\mathrm{EB}, r}$ & $\begin{array}{l}\text { Thermoelectric conversion efficiency } \\
\text { of the electric boiler. }\end{array}$ \\
\hline$P_{\text {tie }, r, l}^{\max }$ & $\begin{array}{l}\text { Maximum transmission power of tie } \\
\text { line } l \text {. }\end{array}$ & $\varphi$ & Price of purchasing power per unit. \\
\hline$P_{\mathrm{L}, r, t}^{s}$ & Electric power of loads. & $\rho_{1}$ & $\begin{array}{l}\text { Penalty price for } \mathrm{CHP} \text { units deviating } \\
\text { from their planned outputs. }\end{array}$ \\
\hline$Q_{\mathrm{L}, t}$ & Refrigeration power. & $\rho_{2}$ & $\begin{array}{l}\text { Penalty price for purchasing power } \\
\text { deviating from its planned } \\
\text { purchasing power. }\end{array}$ \\
\hline $\begin{array}{l}Q_{\mathrm{EC}, r, \min ^{\prime}}^{s} \\
Q_{\mathrm{EC}, r, \max }^{s}\end{array}$ & $\begin{array}{l}\text { Minimum and maximum cooling } \\
\text { output of the electric refrigerator. }\end{array}$ & $\rho_{3}$ & $\begin{array}{l}\text { Penalty price for abandoned } \mathrm{WT} \text { and } \\
\text { PV power. }\end{array}$ \\
\hline$\widetilde{T}_{\mathrm{n}, r, \min }^{s} \widetilde{T}_{\mathrm{n}, r, \max }^{s}$ & $\begin{array}{l}\text { Lower and the upper limits of } \\
\text { indoor temperature of } \\
\text { cooling buildings. }\end{array}$ & $\mu_{1}, \mu_{2}$ & $\begin{array}{l}\text { Lower limit and the upper limit of the } \\
\text { heating supply elasticity. }\end{array}$ \\
\hline \multicolumn{4}{|l|}{ (3) Variables } \\
\hline$D$ & Equivalent thermal resistance. & $P_{\text {tie }, l, t}^{s}$ & Transmission power of the tie line $l$. \\
\hline$E_{r, t}$ & Charging capacity of EVs. & $\begin{array}{l}P_{\mathrm{PW}, r, t, \max ^{\prime}}^{\mathcal{S}} \\
P_{\mathrm{PV}, r, t, \max }^{S}\end{array}$ & Maximum output of WT and PV. \\
\hline$H_{\mathrm{chp}, r, i, t}^{s}$ & Heating output of $\mathrm{CHP}$ unit. & $\begin{array}{l}P_{\mathrm{PWH}, r, t^{\prime}}^{S} \\
P_{\mathrm{PVH}, r, t}^{s}\end{array}$ & $\begin{array}{l}\text { Power for heating supplied by WT } \\
\text { and PV. }\end{array}$ \\
\hline$H_{\mathrm{EB}, r, t}^{s}$ & Heating output of the electric boiler. & $\begin{array}{l}P_{\mathrm{PW}, r, t^{\prime}}^{S} \\
P_{\mathrm{PV}, r, t}^{S}\end{array}$ & Power supplied by WT and PV. \\
\hline$P_{\mathrm{EC}, r, t}^{s}$ & Electric refrigerator power. & $Q_{\mathrm{EC}, r, t}^{s}$ & Cooling power of electric refrigerator. \\
\hline$P_{\mathrm{ch}, r, t}$ & Charging power of EVs. & $T^{\prime}$ & Adjustable heating durations. \\
\hline$P_{\text {buy }, r, t}^{s}$ & Purchasing power. & $T_{\mathrm{h}, t}$ & $\begin{array}{l}\text { Return water temperature of the } \\
\text { heating network. }\end{array}$ \\
\hline$P_{\text {buy }, r, t}^{0}$ & Planned purchasing power. & $T_{\mathrm{n}, t}, \widetilde{T}_{\mathrm{n}, t}$ & $\begin{array}{l}\text { Indoor temperature of } \\
\text { heating/cooling buildings. }\end{array}$ \\
\hline$P_{\text {chp }, r, i, t}^{s}$ & Electric output of CHP unit. & $t_{\mathrm{a}}$ & $\begin{array}{l}\text { Air temperature around the } \\
\text { human body. }\end{array}$ \\
\hline$P_{\mathrm{chp}, r, i, t}^{0}$ & Planned electric output of $\mathrm{CHP}$ unit. & $\chi_{r}^{s}$ & $\begin{array}{l}\text { Relation coefficient of heating } \\
\text { capacity and the difference between } \\
\text { supply/return water temperature. }\end{array}$ \\
\hline$P_{\mathrm{cut}, r, t}^{\mathrm{s}}$ & Abandoned WT and PV power. & $\lambda_{r, P M V, t}^{s}$ & PMV index. \\
\hline
\end{tabular}

\section{Appendix A}

Table A1. Power capacities of multiple functional areas.

\begin{tabular}{lcccc}
\hline & Residential Area & Office Area & Commercial Area & Industrial Area \\
\hline CHP (MW) & 15 & 12 & 12 & 35 \\
WT (MW) & 15 & 0 & 0 & 35 \\
PV (MW) & 30 & 35 & 30 & 70 \\
\hline
\end{tabular}

Table A2. Parameters of CHP units.

\begin{tabular}{cccc}
\hline Functional Areas & $\begin{array}{c}\text { Maximum Power } \\
\text { Generation/(MW) }\end{array}$ & $\begin{array}{c}\text { Minimum Power } \\
\text { Generation/(MW) }\end{array}$ & Ramp Rate/(MW/h) \\
\hline Residential Area & 15 & 3 & 4.5 \\
Office Area & 12 & 2.4 & 3.6 \\
Commercial Area & 12 & 2.4 & 3.6 \\
Industrial Area & 35 & 7 & 10.5 \\
\hline
\end{tabular}


Table A3. Parameters of EVs.

\begin{tabular}{|c|c|c|c|c|c|c|}
\hline \multirow[b]{2}{*}{ Time Period } & \multicolumn{3}{|c|}{ Residential Area } & \multicolumn{3}{|c|}{ Office Area } \\
\hline & $\begin{array}{c}{\left[P_{\mathrm{ch}, r, t}^{\min } P_{\mathrm{ch}, r, t}^{\max }\right]} \\
/(\mathrm{MW})\end{array}$ & {$\left[\alpha_{r, k}^{\min }, \alpha_{r, k}^{\max }\right]$} & $\begin{array}{c}E_{r, k}^{a v} \\
/(\mathbf{M W} \cdot \mathbf{h})\end{array}$ & $\begin{array}{l}{\left[P_{\mathrm{ch}, r, t^{\prime}}^{\min } P_{\mathrm{ch}, r, t}^{\max }\right]} \\
\quad /(\mathbf{M W})\end{array}$ & {$\left[\alpha_{r, k}^{\min }, \alpha_{r, k}^{\max }\right]$} & $\begin{array}{c}E_{r, k}^{a v} \\
/(\mathbf{M W} \cdot \mathbf{h})\end{array}$ \\
\hline 8 a.m. -5 p.m. & {$[0,0.5]$} & {$[0.7,1.3]$} & 2.43 & {$[0,2]$} & {$[0.7,1.3]$} & 1.83 \\
\hline 6 p.m. -9 p.m. & {$[0,1.5]$} & {$[0.7,1.3]$} & 3.64 & {$[0,0.75]$} & {$[0.7,1.3]$} & 2.43 \\
\hline 10 p.m. -7 a.m. & {$[0,3]$} & {$[0.7,1.3]$} & 11.41 & {$[0,0.5]$} & {$[0.7,1.3]$} & 9.71 \\
\hline \multirow[b]{2}{*}{ Time Period } & \multicolumn{3}{|c|}{ Commercial Area } & \multicolumn{3}{|c|}{ Industrial Area } \\
\hline & $\begin{array}{l}{\left[P_{\mathrm{ch}, r, t^{\prime}}^{\min } P_{\mathrm{ch}, r, t}^{\max }\right]} \\
/(\mathrm{MW})\end{array}$ & {$\left[\alpha_{r, k}^{\min }, \alpha_{r, k}^{\max }\right]$} & $\begin{array}{c}E_{r, k}^{a v} \\
/(\mathrm{MW} \cdot \mathrm{h})\end{array}$ & $\begin{array}{c}{\left[P_{\mathrm{ch}, r, t^{\prime}}^{\min } P_{\mathrm{ch}, r, t}^{\max }\right]} \\
/(\mathbf{M W})\end{array}$ & {$\left[\alpha_{r, k}^{\min }, \alpha_{r, k}^{\max }\right]$} & $\begin{array}{c}E_{r, k}^{a v} \\
/(\mathbf{M W} \cdot \mathbf{h})\end{array}$ \\
\hline 8 a.m. -5 p.m. & {$[0,0.5]$} & {$[0.7,1.3]$} & 2.43 & {$[0,2]$} & {$[0.7,1.3]$} & 9.71 \\
\hline 6 p.m. -9 p.m. & {$[0,2.2]$} & {$[0.7,1.3]$} & 5.47 & {$[0,0.38]$} & {$[0.7,1.3]$} & 0.91 \\
\hline 10 p.m. -7 a.m. & {$[0,0.5]$} & {$[0.7,1.3]$} & 2.43 & {$[0,0.5]$} & {$[0.7,1.3]$} & 2.43 \\
\hline
\end{tabular}

Table A4. Operating parameters of the IES.

\begin{tabular}{|c|c|c|c|c|c|}
\hline $\begin{array}{c}a_{0,1} /(\$) \\
1650\end{array}$ & $\begin{array}{c}a_{1,1} /(\$ /(\mathbf{M W} \cdot \mathbf{h})) \\
1450\end{array}$ & $\begin{array}{c}a_{2,1} /(\$ /(\mathbf{M W} \cdot \mathbf{h})) \\
420\end{array}$ & $\begin{array}{c}\left.\boldsymbol{a}_{3,1} /(\mathbf{( \$} / \mathbf{M W} \cdot \mathbf{h})^{\mathbf{2}}\right) \\
345\end{array}$ & $\begin{array}{c}\boldsymbol{a}_{4,1} /\left(\mathbf{( \$} /(\mathbf{M W} \cdot \mathbf{h})^{\mathbf{2}}\right) \\
30\end{array}$ & $\begin{array}{c}a_{5,1} /\left(\left(\$ /(\mathbf{M W} \cdot \mathbf{h})^{2}\right)\right. \\
31\end{array}$ \\
\hline /(\$/(MW·h)) & $\rho_{1} /(\$ /(\mathbf{M W} \cdot \mathbf{h}))$ & $\rho_{2} /(\$ /(M W \cdot h))$ & $\rho_{3} /(\$ /(\mathbf{M W} \cdot \mathbf{h}))$ & $k_{h p}$ & $P_{r, l}^{\max } /(\mathrm{MW})$ \\
\hline 550 & 60 & 50 & 100 & 2.62 & 5 \\
\hline$H_{\mathrm{EB}, 1}^{\max } /(\mathrm{MW})$ & $H_{\mathrm{EB}, 2}^{\max } /(\mathrm{MW})$ & $H_{\mathrm{EB}, 3}^{\max } /(\mathrm{MW})$ & $H_{\mathrm{EB}, 4}^{\max } /(\mathrm{MW})$ & $\eta_{r, \mathrm{~EB}}$ & $\chi_{1} /\left(\mathrm{MW} /{ }^{\circ} \mathrm{C}\right)$ \\
\hline 25 & 15 & 15 & 35 & 0.9 & 0.55 \\
\hline $\begin{array}{c}\chi_{2} /\left(\mathbf{M W} /{ }^{\circ} \mathbf{C}\right) \\
0.45\end{array}$ & $\begin{array}{c}\chi_{3} /\left(\mathbf{M W} /{ }^{\circ} \mathbf{C}\right) \\
0.35\end{array}$ & $\begin{array}{c}T_{r, g, \max } /\left({ }^{\circ} \mathrm{C}\right) \\
120.0\end{array}$ & $\begin{array}{c}Q_{\mathrm{EC}, 3, \min } /(\mathrm{MW}) \\
0\end{array}$ & $\begin{array}{c}Q_{\mathrm{EC}, 3, \max } /(\mathrm{MW}) \\
20\end{array}$ & $\underset{0}{Q_{\mathrm{EC}, 4, \min } /(\mathrm{MW})}$ \\
\hline $\begin{array}{c}Q_{\mathrm{EC}, 4, \max } /(\mathrm{MW}) \\
30\end{array}$ & $\begin{array}{c}\widetilde{T}_{\mathbf{n}, 3, \min } /\left({ }^{\circ} \mathrm{C}\right) \\
-18.0\end{array}$ & $\begin{array}{c}\widetilde{T}_{\mathbf{n}, 3, \max } /\left({ }^{\circ} \mathbf{C}\right) \\
-10.0\end{array}$ & $\begin{array}{c}\widetilde{T}_{\mathbf{n}, 4, \min } /\left({ }^{\circ} \mathrm{C}\right) \\
-20.0\end{array}$ & $\begin{array}{c}\widetilde{T}_{\mathbf{n}, 4, \max } /\left({ }^{\circ} \mathbf{C}\right) \\
-15.0\end{array}$ & $\begin{array}{c}D /\left({ }^{\circ} \mathrm{C} / \mathrm{MW}\right) \\
2\end{array}$ \\
\hline $\begin{array}{c}\mathrm{C} /\left(\mathrm{MW} \cdot \mathrm{h} /{ }^{\circ} \mathrm{C}\right) \\
0.54\end{array}$ & $\begin{array}{c}\eta_{\mathrm{EC}, \mathrm{r}} \\
3.0\end{array}$ & $\begin{array}{c}\lambda \\
0.3\end{array}$ & $\begin{array}{l}\mu_{1} \\
0.8\end{array}$ & $\begin{array}{l}\mu_{2} \\
1.2\end{array}$ & $\begin{array}{l}- \\
-\end{array}$ \\
\hline
\end{tabular}

Table A5. Parameters of the PMV index.

\begin{tabular}{cccc}
\hline$M /\left(\mathbf{W} / \mathbf{m}^{2}\right)$ & $W /\left(\mathbf{W} / \mathrm{m}^{2}\right)$ & $\boldsymbol{P}_{\mathrm{a}} /(\mathbf{P a})$ & $\left.t_{\mathrm{b}} /{ }^{\circ} \mathrm{C}\right)$ \\
70.0 & 0.0 & 2000.0 & 29.7 \\
\hline$t_{\mathrm{cl}} /\left({ }^{\circ} \mathrm{C}\right)$ & $f_{\mathrm{cl}}$ & $h_{\mathrm{c}} /\left(\mathrm{W} /\left(\mathrm{m}^{2} \cdot \mathrm{K}\right)\right)$ & - \\
32.0 & 1.15 & 4.7 & - \\
\hline
\end{tabular}

Table A6. Coefficients of the ARMA model of heating systems $(J=2)$.

\begin{tabular}{ccccccc}
\hline$j$ & $\alpha_{j}$ & $\beta_{j}$ & $\gamma_{j}$ & $\theta_{j}$ & $\varphi_{j}$ & $\omega_{j}$ \\
\hline 0 & - & 0.2112 & 0.3317 & - & - & - \\
1 & 0.5721 & -0.0243 & -0.3169 & 0.6991 & 0.1011 & 0.1998 \\
2 & 0.0607 & -0.0104 & 0.1741 & - & - & - \\
\hline
\end{tabular}

Table A7. Initial operation values of heating/cooling systems.

\begin{tabular}{cccc}
\hline$T_{\mathrm{g}, 0} /\left({ }^{\circ} \mathrm{C}\right)$ & $T_{\mathrm{g},-1} /\left({ }^{\circ} \mathrm{C}\right)$ & $T_{\mathrm{n}, 0} /\left({ }^{\circ} \mathrm{C}\right)$ & $T_{\mathrm{n},-1} /\left({ }^{\circ} \mathrm{C}\right)$ \\
75.0 & 75.0 & 25.0 & 25.0 \\
\hline$T_{\mathrm{w}, 0} /\left({ }^{\circ} \mathrm{C}\right)$ & $T_{\mathrm{w},-1} /\left({ }^{\circ} \mathrm{C}\right)$ & $\widetilde{T}_{\mathrm{n} 0,3} /\left({ }^{\circ} \mathrm{C}\right)$ & $\widetilde{T}_{\mathrm{n} 0,4} /\left({ }^{\circ} \mathrm{C}\right)$ \\
0.0 & 0.0 & -10.0 & -10.0 \\
\hline
\end{tabular}


Table A8. Typical daily loads and outdoor temperature data of multiple functional areas in winter.

\begin{tabular}{cccccc}
\hline Time & $\begin{array}{c}\text { Electric Loads } \\
\text { of Residential } \\
\text { Area/(MW) }\end{array}$ & $\begin{array}{c}\text { Electric Loads } \\
\text { of Office } \\
\text { Area/(MW) }\end{array}$ & $\begin{array}{c}\text { Electric Loads } \\
\text { of Commercial } \\
\text { Area/(MW) }\end{array}$ & $\begin{array}{c}\text { Electric Loads } \\
\text { of Industrial } \\
\text { Area/(MW) }\end{array}$ & $\begin{array}{c}\text { Outdoor } \\
\left.\text { Temperature/( }{ }^{\circ} \text { ) }\right)\end{array}$ \\
\hline 1 & 17.74 & 7.70 & 11.03 & 34.85 & -2.0 \\
2 & 13.62 & 7.43 & 10.24 & 33.88 & -2.0 \\
3 & 12.38 & 7.15 & 9.45 & 34.85 & -2.0 \\
4 & 11.55 & 7.15 & 8.93 & 35.82 & -4.0 \\
5 & 10.73 & 6.16 & 6.72 & 34.85 & -4.0 \\
6 & 12.38 & 5.72 & 7.14 & 35.82 & -4.0 \\
7 & 14.44 & 5.94 & 7.56 & 34.85 & -4.0 \\
8 & 19.39 & 17.6 & 14.45 & 53.01 & -2.0 \\
9 & 24.75 & 22.00 & 22.26 & 70.29 & -1.0 \\
10 & 20.63 & 41.80 & 24.36 & 77.21 & 0.0 \\
11 & 16.50 & 39.05 & 26.46 & 82.97 & 3.0 \\
12 & 11.14 & 37.40 & 28.56 & 88.74 & 4.0 \\
13 & 10.73 & 36.30 & 30.24 & 82.97 & 7.0 \\
14 & 10.32 & 35.75 & 28.14 & 89.88 & 7.0 \\
15 & 9.90 & 34.65 & 21.17 & 84.13 & 8.0 \\
16 & 9.90 & 33.00 & 21.50 & 77.21 & 8.0 \\
17 & 9.08 & 30.25 & 21.84 & 71.45 & 7.0 \\
18 & 14.44 & 32.45 & 22.85 & 51.85 & 5.0 \\
19 & 22.69 & 17.60 & 31.92 & 42.64 & 5.0 \\
20 & 30.94 & 9.63 & 31.50 & 32.91 & 2.0 \\
21 & 38.78 & 9.08 & 23.52 & 33.88 & -1.0 \\
22 & 36.30 & 8.25 & 19.49 & 33.88 & -1.0 \\
23 & 27.23 & 6.16 & 17.14 & 33.88 & 34.85 \\
24 & 23.93 & 5.72 & 15.12 & & \\
\hline
\end{tabular}

Table A9. The continuous probability distributions of WT/PV.

\begin{tabular}{ccc}
\hline Time & WT/(MW) & PV/(MW) \\
\hline 1 & $N\left(0.707,0.136^{2}\right)$ & 0 \\
2 & $N\left(0.769,0.150^{2}\right)$ & 0 \\
3 & $N\left(0.862,0.188^{2}\right)$ & 0 \\
4 & $N\left(0.923,0.186^{2}\right)$ & 0 \\
5 & $N\left(0.785,0.214^{2}\right)$ & $N\left(0.267,0.140^{2}\right)$ \\
6 & $N\left(0.662,0.199^{2}\right)$ & $N\left(0.289,0.145^{2}\right)$ \\
7 & $N\left(0.554,0.189^{2}\right)$ & $N\left(0.378,0.139^{2}\right)$ \\
8 & $N\left(0.400,0.143^{2}\right)$ & $N\left(0.533,0.206^{2}\right)$ \\
9 & $N\left(0.600,0.240^{2}\right)$ & $N\left(0.711,0.280^{2}\right)$ \\
10 & $N\left(0.569,0.241^{2}\right)$ & $N\left(0.822,0.334^{2}\right)$ \\
11 & $N\left(0.585,0.278^{2}\right)$ & $N\left(0.844,0.346^{2}\right)$ \\
12 & $N\left(0.600,0.285^{2}\right)$ & $N\left(0.956,0.352^{2}\right)$ \\
13 & $N\left(0.600,0.292^{2}\right)$ & $N\left(0.956,0.399^{2}\right)$ \\
14 & $N\left(0.508,0.264^{2}\right)$ & $N\left(0.911,0.397^{2}\right)$ \\
15 & $N\left(0.538,0.273^{2}\right)$ & $N\left(0.800,0.334^{2}\right)$ \\
16 & $N\left(0.508,0.270^{2}\right)$ & $N\left(0.667,0.360^{2}\right)$ \\
17 & $N\left(0.415,0.225^{2}\right)$ & $N\left(0.511,0.280^{2}\right)$ \\
18 & $N\left(0.462,0.223^{2}\right)$ & $N\left(0.511,0.278^{2}\right)$ \\
19 & $N\left(0.554,0.294^{2}\right)$ & $N\left(0.311,0.157^{2}\right)$ \\
20 & $N\left(0.615,0.297^{2}\right)$ & $N\left(0.222,0.117^{2}\right)$ \\
21 & $N\left(0.723,0.309^{2}\right)$ & 0 \\
22 & $N\left(0.600,0.267^{2}\right)$ & 0 \\
23 & $N\left(0.692,0.263^{2}\right)$ & 0 \\
24 & $N\left(0.800,0.312^{2}\right)$ & 0 \\
\hline & &
\end{tabular}




\section{References}

1. Lin, Z.Z.; Wen, F.S.; Ding, Y.; Xue, Y.S.; Liu, S.Y.; Zhao, Y.X.; Yi, S.M. WAMS-based coherency detection for situational awareness in power systems with renewables. IEEE Trans. Power Syst. 2018, 33, 5410-5426. [CrossRef]

2. Wind Power Grid-Connected Operation in 2017; The National Energy Administration of the P.R.C.: Beijing, China, 2018.

3. Mehrasa, M.; Pouresmaeil, E.; Soltani, H.; Blaabjerg, F.; Calado, M.R.A.; Catalão, J.P.S. Virtual inertia and mechanical power-based control strategy to provide stable grid operation under high renewables penetration. Appl. Sci. 2019, 9, 1043. [CrossRef]

4. Shu, Y.; Zhang, Z.G.; Guo, J.B.; Zhang, Z.L. Study on key factors and solution of renewable energy accommodation. Chin. J. Proc. Csee 2017, 37, 1-9.

5. Dong, X.; Quan, C.; Jiang, T. Optimal planning of integrated energy systems based on coupled CCHP. Energies 2018, 11, 2621. [CrossRef]

6. Dominković, D.F.; Krajačić, G. District cooling versus individual cooling in urban energy systems: The impact of district energy share in cities on the optimal storage sizing. Energies 2019, 12, 407. [CrossRef]

7. Chen, X.; Kang, C.; O'Malley, M.; Xia, Q.; Bai, J.; Liu, C.; Sun, R.; Wang, W.; Li, H. Increasing the flexibility of combined heat and power for wind power integration in China: Modeling and implications. IEEE Trans. Power Syst. 2015, 30, 1848-1857. [CrossRef]

8. Chen, H.K.; Yu, Y.J.; Jiang, X. Optimal scheduling of combined heat and power units with heat storage for the improvement of wind power integration. In Proceedings of the 2016 IEEE Asia-Pacific Power and Energy Conference, Xi'an, China, 25-28 October 2016; pp. 1508-1512.

9. Li, Z.; Wu, W.; Shahidehpour, M.; Wang, J.; Zhang, B. Combined heat and power dispatch considering pipeline energy storage of district heating network. IEEE Trans. Sustain. Energy 2016, 7, 12-22. [CrossRef]

10. Molitor, C.; Marin, M.; Hernandez, L.; Monti, A. Decentralized coordination of the operation of residential heating unit. In Proceedings of the Innovative Smart Grid Technologies Europe, Lyngby, Denmark, 6-9 October 2013; pp. 1-5.

11. Merkert, L.; Haime, A.A.; Hohmann, S. Optimal scheduling of combined heat and power generation units using the thermal inertia of the connected district heating grid as energy storage. Energies 2019, $12,266$. [CrossRef]

12. Mart, V.D.K.; Van, S.W. Smart charging of electric vehicles with photovoltaic power and vehicle-to-grid technology in a microgrid; a case study. Appl. Energy 2015, 152, 20-30.

13. Erdinc, O. Economic impacts of small-scale own generating and storage units, and electric vehicles under different demand response strategies for smart households. Appl. Energy 2014, 126, 142-150. [CrossRef]

14. Huang, H.; Liang, D.; Tong, Z. Integrated energy microgrid planning using electricity, heating and cooling demands. Energies 2018, 11, 2810. [CrossRef]

15. Tang, B.; Gao, G.; Xia, X.; Yang, X. Integrated energy system configuration optimization for multi-zone heat-supply network interaction. Energies 2018, 11, 3052.

16. Wu, Q.H.; Zheng, J.H.; Jing, Z.X. Coordinated scheduling of energy resources for distributed DHCs in an integrated energy grid. Csee J. Power Energy Syst. 2015, 1, 95-103. [CrossRef]

17. Regulations for the Evaluation of Urban Land Intensive Utilization Potential; The Ministry of Land and Resources of the P.R.C.: Beijing, China, 2007.

18. Porter, R.W. Economic distribution distance for cogenerated district heating and cooling. Energy 1985, 10, 851-859. [CrossRef]

19. Fanger, P.O. Thermal Comfort; McGraw-Hill Company: New York, NY, USA, 1970.

20. Fanger, P.O.; Toftum, J. Extension of the PMV model to non-air-conditioned buildings in warm climates. Energy Build. 2002, 34, 533-536. [CrossRef]

21. Design Code for Heating Ventilation and Air Conditioning; The Ministry of Construction of the PRC: Beijing, China, 2004.

22. Fu, L.; Jiang, Y. Optimal operation of a CHP plant for space heating as a peak load regulating plant. Energy 2000, 25, 283-298.

23. Xia, B. The Research of Economy Cooling area and the Maximum Conveying Distance in District Cooling System; Hunan University: Changsha, China, 2014. 
24. Yu, Z.; Ning, L. Parameter selection for a centralized thermostatically controlled appliances load controller used for intra-hour load balancing. IEEE Trans. Smart Grid 2013, 4, 2100-2108.

25. Wang, S.; Feng, Y.X.; Deng, W.X.; Zhou, G.; Sheng, P.F. Electric vehicle charging load forecast considering time-space characteristic distribution. Chin. J. Zhejiang Electr. Power 2016, 35, 15-20.

26. Liu, S.; Fu, X.H.; Ye, C.J.; Huang, M.X. Spatial load clustering and integrated forecasting method of distribution network considering regional difference. Chin. J. Autom. Electr. Power Syst. 2017, 41, 70-75.

27. Zhang, H.C.; Hu, Z.C.; Song, Y.H.; Xu, Z.; Jia, L. A prediction method for electric vehicle charging load considering spatial and temporal distribution. Chin. J. Autom. Electr. Power Syst. 2014, 38, 13-20.

28. Zhao, Y.X.; Lin, Z.Z.; Ding, Y.; Liu, Y.L.; Sun, L.; Yan, Y. A model predictive control based generator start-up optimization strategy for restoration with microgrids as black-start resources. IEEE Trans. Power Syst. 2018, 33, 7189-7203. [CrossRef]

29. Zhang, Y.; Gatsis, N.; Giannakis, G.B. Robust energy management for microgrids with high-penetration renewables. IEEE Trans. Sustain. Energy 2013, 4, 944-953. [CrossRef]

30. Hosseinzadeh, M.; Salmasi, F.R. Robust optimal power management system for a hybrid AC/DC micro-grid. IEEE Trans. Sustain. Energy 2015, 6, 675-687. [CrossRef]

31. Lara, J.D.; Olivares, D.E.; Canizares, C.A. Robust energy management of isolated microgrids. IEEE Syst. J. 2019, 13, 680-691. [CrossRef]

32. Lin, Z.Z.; Wen, F.S.; Xue, Y.S. A restorative self-healing algorithm for transmission systems based on complex network theory. IEEE Trans. Smart Grid 2016, 7, 2154-2162. [CrossRef]

(C) 2019 by the authors. Licensee MDPI, Basel, Switzerland. This article is an open access article distributed under the terms and conditions of the Creative Commons Attribution (CC BY) license (http://creativecommons.org/licenses/by/4.0/). 